\title{
Seeing Themselves: Cultural Identity and New Zealand Produced Children's Television
}

\author{
Ngaire Shepherd
}

A Thesis Submitted to Victoria University of Wellington in Fulfilment of the Requirements for the Degree of Master of Arts in Media Studies

April 2008 


\section{Acknowledgements}

First and foremost this project would not have been possible without the commitment from the funders, producers and children that agreed to be interviewed. Thank you for your valuable contributions.

For my supervisors, Joost and Sue, thank you for your support and guidance, and for your ability to understand my first drafts (most of the time).

Rosie and Paul, thank you for your supplies of caffeine and for making life in the media studies villa far more interesting, particularly Rosie's underappreciated ability to dance through her stress in my office.

My parents and Dave, thank you for dealing with my distraction and inability to make sense a lot of the time, and of course all the whinging.

And Daniel, thank you for dealing with all of the above, and everything else I have thrown at you during this process. 


\begin{abstract}
The New Zealand television environment is a complex one, and its ability to instil a sense of 'cultural identity' for New Zealand viewers has been regularly debated. Local children's programming is an area that can sometimes be overlooked in these important discussions. Children's programming in New Zealand is almost entirely publicly funded and is therefore legislatively tied to 'reflecting' cultural identity for a New Zealand child audience. This raises questions about how cultural identity is defined and understood within this industry, especially considering the inherent differences between a child audience and adult programme makers. These questions are engaged with through an examination of how cultural identity is discussed by funders, producers and audiences of four locally produced television brands: What Now?, Sticky TV, Studio 2 and Pukana. This thesis considers cultural identity to be a social construction that is both fluid and, in a New Zealand context, tied to certain expectations of 'New Zealandness'. This fluidity is examined through a discourse analysis of how funders, producers and audiences talk about each programme as well as cultural identity, in order to examine similarities and differences in how each group conceptualises this important funding concept. The argument is formed that cultural identity is understood in different terms: for children cultural identity is foremost about belonging to and 'seeing themselves' in a larger community of New Zealand children, while programme makers are concerned with the problematic notion of 'reflecting' "kids' worlds".
\end{abstract}




\section{Contents}

Chapter One - Conceptual Frameworks 3

Chapter Two - Methodology 19

Chapter Three - Industry Interviews. 37

Chapter Four - Audience Interviews. .72

Chapter Five - Reflection versus Community Creation. .95

Bibliography 110

Appendices. 116 


\section{Chapter One - Conceptual Framework}

[New Zealand] On Air will take a leadership role in providing a safe, quality programming environment for New Zealanders of all ages by promoting an increasing number of diverse, innovative children's programmes that reflect and foster the different expressions of New Zealand's cultural identity and serve the needs of children as citizens, not simply consumers. ${ }^{1}$

In June 2000 New Zealand On Air (NZOA) released a new Children's Programming Strategy in response to what was seen as a "serious decline"2 in the amount of children's television produced in New Zealand. As NZOA is the primary source of funding for this programming, this strategy illustrates that children's programming produced in New Zealand is generally required to "reflect and foster the different expressions of New Zealand's cultural identity". This is a broad statement that raises a number of questions: What is meant by cultural identity here? Who is defining it? What constitutes an expression of cultural identity? Why is this important for children?

This research is an examination of the discourses of cultural identity that creators and audiences of local children's programming use to give meaning to the genre and its relationship with cultural identity. The New Zealand broadcasting environment is characterised by a particularly unique relationship between those who fund programmes (predominantly NZOA, but network support is needed), the producer and the audience. It is in this triangle of funder, producer and audience that cultural identity is conceptualised, expressed and interpreted. Therefore this research will explore cultural identity by examining the different discourses that funders, producers and audiences use to conceptualise and understand the concept.

This chapter will provide the conceptual framework for research into the articulation and reception of cultural identity in locally produced children's programming. There are a number

${ }^{1}$ NZ On Air, (2000). NZ On Air Children's Programming Strategy, available at <www.nzonair.govt.nz> version current at $26 / 2 / 08$.

$2 \mathrm{lbid}$ 
of discussions that need to be explored to frame an analysis of how funders, producers and audience discuss cultural identity. The key issues here are: the current broadcasting context for children's television in New Zealand; an acknowledgement of larger debates surrounding children and television; and finally definitions of cultural identity and the difficulty of reflecting a 'New Zealand culture'.

\section{The New Zealand Broadcasting Context.}

The strategy from NZOA that opens this chapter illustrates the unique requirements for locally produced programming. In order to receive NZOA funding, there is an expectation that local programming will 'reflect culture' and have some kind of cultural value or meaning for a New Zealand audience. This section will outline the complexities of the mixed model broadcasting system in New Zealand to contextualise the funder, producer and audience relationship. It will also address the importance placed on local content creation for the wider New Zealand audience and more specifically for children.

\section{Local Content as a Public Service}

The mixed model of broadcasting refers to the combination of public service and commercial revenue streams. What makes this model particularly complex is that strictly speaking New Zealand no longer has a public service broadcaster. Originally serviced by a direct licence fee, a period of deregulation in the 1980s has resulted in the nation's state owned broadcaster (TVNZ) gathering 90 percent of its revenue through advertising and only receiving a small amount (less than ten percent) of direct public funding through a public service Charter (introduced in 2003). ${ }^{3}$ This has meant a shift from the traditional public service focus of providing informative and educational broadcasting for an audience as citizens, to a commercial focus on entertainment and maximising advertising revenue. ${ }^{4}$ To combat the damage to public service ideals during deregulation, NZOA (formerly the

3 TVNZ (2007). A Successful Past, an Exciting Future, TVNZ Corporate Brochure February 2007, available at $<$ http://tvnz.co.nz/view/about_tvnz_index_skin/816472> version current at 28/3/08, p.2.

${ }^{4}$ Norris, Paul (2004). "Reshaping Public Broadcasting: the New Zealand Experience 1988-2003" available at Institute of Public Policy Research, <http://www.ippr.org.uk/uploadedFiles/projects/NorrisNZ2.PDF> version current at 28/3/08, pp. 3-4. 
Broadcasting Commission) was set up to ensure a place for the "social objectives" 5 in a broadcasting environment that was becoming increasingly commercialised. These "social objectives" are still evident in NZOA's mission statement, "to reflect and foster the development of New Zealand culture and identity through broadcasting". 6 Accordingly, the fostering of local content and cultural expression became directly tied to public service ideals through this use of a public funding body. This has resulted in, as Graham Murdock argues, public service television in New Zealand being foremost about the provision of local content. ${ }^{7}$

Children's programming provides an example of the way that New Zealand on Air is used to exact the "social objectives" of public service television in a predominantly commercial environment. Children's programming is not commissioned by television channels without significant financial assistance from funding agency NZOA and is therefore bound to a particular set of criteria, principally cultural identity.

Considering this emphasis on culture, a position that requires consideration in New Zealand broadcasting debates is that of Māori. The only essentially public service broadcaster in New Zealand is currently Māori Television (MTS). Going to air in May 2004 it is designed to contribute to the revitalisation and normalisation of Māori tikanga and te reo for all New Zealanders. ${ }^{8}$ As a culturally specific broadcaster, the commercial appeal for the channel is small, and it relies heavily on funding distributed by government agencies Te Puni Kōkiri and Te Māngai Pāho.

As the indigenous people of New Zealand, particular provisions are made for the maintenance and promotion of Māori culture through broadcasting. There is often an expectation, however, that Māori programming should consider a mainstream audience. ${ }^{9}$ This example of "bicultural" broadcasting policy raises questions about how Māori content is

\footnotetext{
${ }^{5}$ Norris, $\mathrm{p} 4$.

${ }^{6} \mathrm{NZOA}$, About Us, available at <www.nzonair.govt.nz/about_us.php> version current at 28/2/08.

${ }^{7}$ Murdock, Graham (1997) "Public Broadcasting in Privatised Times: Rethinking the New Zealand Experiment" in Paul Norris and John Farnsworth (eds), Keeping It Ours: Issues of Television broadcasting in New Zealand, Christchurch: New Zealand Broadcasting School, Christchurch Polytechnic, p. 24.

${ }^{8}$ Māori Television, Corporate Māori Television: About, available at < http://corporate.Māoritelevision.com/about.htm> version current at 28/3/08.

9 Under the Broadcasting Act of 1989 NZOA has a responsibility to promote Māori language and culture for a mainstream audience, see New Zealand On Air - Mãori Television available at < http://www.nzonair.govt.nz/Māori_television.php> version current at 7/3/08.
} 
framed. Official biculturalism has been described by Fleras as a "focus on institutional accommodation by incorporating a Māori dimension into state practices and national symbols"10. Through the requirements of The Broadcasting Act, NZOA arguably fits this definition through their need to consider a mainstream audience for Māori content due to a focus on reaching as large an audience as possible. ${ }^{11}$ This relegates Māori content in programming as a signifier of cultural identity rather than to reflect and engage a Māori audience.

This framing of Māori for a mainstream audience illustrates the complexities of being able to 'reflect' cultural identity in this kind of funding environment. Debates about local content inevitably draw on the need for a New Zealand audience to be able to see and hear themselves on screen, as exemplified by this quote from Hamish Keith used to open Trisha Dunleavy's book on New Zealand drama:

Unless we see ourselves alongside the rest of the world on our television screens we might begin to think we have no value or we don't exist. To establish our value and give us an existence is really what television should be all about. ${ }^{12}$

This statement also demonstrates the kind of inclusive language that is used when discussing local content and cultural identity that masks the potential for exclusion. The way that national cultural identity is framed, on the other hand, as being exclusive and predominantly Pākehā focussed will be explored further in later parts of this chapter. It is also necessary to examine why this sense of "seeing ourselves" is the central focus of New Zealand produced programming.

\section{The Impact of Imported Programming}

New Zealand is predominantly an English-speaking country with a small market size (4 million) as compared with the United States (303 million) or Britain (60 million). ${ }^{13}$ As a result

\footnotetext{
10 Fleras, Augie (1998). "Working through Differences" in New Zealand Sociology, 13(1), p.81.

${ }_{11}$ New Zealand On Air - Māori Television, < http://www.nzonair.govt.nz/Māori_television.php> version current at 7/3/08.

12 Dunleavy,Trisha (2005). Ourselves in Primetime: A History of New Zealand Television Drama, Auckland: Auckland University Press, p.1.
} 
New Zealand television has been vulnerable to the influence of imported programming. ${ }^{14}$ While these imports may be cheap to purchase, they represent some of the highest quality and most successful programmes from leading markets, ${ }^{15}$ making it difficult for New Zealand produced programming to compete. ${ }^{16}$ The small size of the New Zealand market reduces the commercial viability of local television forms, helping to make imported programming a more desirable option for commercially operating networks. ${ }^{17}$ This has left the production of local programming at a disadvantage because it has always had to "compete on an uneven playing field" due to the 'dumping' of these imports into New Zealand's television schedule. ${ }^{18}$

Roger Horrocks has argued that New Zealand made programmes are routinely compared with overseas products of a much higher 'production value', meaning that a local programme has to work hard to gain audience acceptance. This is indicative of how the presence of imported products has been able to influence the judgement and taste of a national audience. In an environment where American and British material have always been "the default setting" and local material the "odd man out"19 there have been unusual challenges to the ability of New Zealand television to represent a sense of New Zealand identity. Horrocks describes this as "cultural cringe", where New Zealand made material is easily rejected by the audience due to lower production values and a level of discomfort when compared with imported material. ${ }^{20}$

Children are exposed to a significant amount of American popular culture and as a group renowned for their ability to pick up new technologies and popular trends very quickly, they can be a difficult audience to cater to. A significant amount of media directed at children foster a connection between popular culture and American culture. Research conducted by Colmar Brunton in 2000 found that New Zealand children did not identify New Zealand shows as 'real shows'; real programmes were American programmes. This study concluded

\footnotetext{
13 lbid p.6.

${ }^{14}$ Horrocks, Roger (2004). "Construction Site: Local Content on Television", Chapter 16 in Roger Horrocks and Nick Perry (eds.) Television in New Zealand: Programming the Nation, Melbourne: Oxford University Press, p.272.

${ }^{15}$ Dunleavy, p.2.

${ }^{16}$ Dunleavy, p.7.

${ }^{17}$ Horrocks, pp.272-3.

18 lbid, p.273.

19 lbid p.281.

20 lbid p.279.
} 
that clearly more children's programmes needed to be funded, and that children needed to be able to "see and hear themselves, their own accent, their own culture". ${ }^{21}$ The study does not, however, elaborate on what this "own culture" may look like and how interested children may be in viewing it.

Zanker has explored this issue of imported products in her research with New Zealand children and their attitudes to media and the impact of imported products:

Brands are increasing sources of cultural identity, 'street cred' and pleasure for children. Children are to be found in the trend-spotting vanguard of consumer culture. $^{22}$

New Zealand children have access to some of the best quality programme brands in the world and are categorised as being an audience that is keen to experiment with new trends. These brands are also becoming increasingly 'global' which originate in the US and are primarily intended for that market but also have licensing and merchandise with a wider global reach. Zanker argues that "without space for local storytelling, children will lose their cultural birthrights and become valued and measured only as consumers with 'nag' value."23 She considers that these brands do not always have the same cultural relevance for a New Zealand audience as they do in their domestic market. This potentially results in, considering the significant proportion of imported product in the children's schedule, greater expectations being placed on the limited amount of local content to provide children with a strong sense of local orientation.

The high proportion of imported programming raises the question of whether or not there is a potential clash between producing programmes that are of interest to 'kiwi kids' and something that might instil a sense of 'cultural identity', and whether the way that

${ }^{21}$ Colmar Brunton (2000). Children and Young People's Attitudes to TV programming and Local Content, Report prepared for New Zealand On Air, available at < http://www.nzonair.govt.nz/files/about/C_YP_Attit.pdf> version current at 23/3/08, pp.33-38.

22 Zanker, Ruth (1999). "Kumara Kai or Big Mac Pack?: Television for Six to 12-year-olds in New Zealand" in John Farnsworth and lan Hutchison (eds) (2001) New Zealand Television: A Reader, Palmerston North: Dunmore Press, p.271.

23 lbid. 
programmes interact with the concept is relevant for children that have access to a variety of global media. This extends to the question whether there can be any kind of unified, recognisable depiction of a New Zealand way of life for children. These kinds of questions demonstrate the need to examine the way that children talk about children's programming and how they specifically engage with locally produced programmes.

The preceding discussion about local content and imported products is symptomatic of larger debates in children's television: firstly regarding the way that children as an audience are discussed and conceptualised, and secondly the influence public service and commercial television systems have on creating 'valuable' programmes for children.

\section{Children and Television}

Messenger-Davies has observed the strange position that children's programming occupies in debates about television. She argues that "[c]hildren's television' is an unusual genre in that its title is defined by the people who watch it, rather than by the characteristics of the text"24. It is a minority genre that has greater expectations placed on it than those regarding television aimed at an older audience. Children's programming is expected to be educational, positive, and generally a constructive use of time for its audience. There is not the same sense of leisure and entertainment that is associated with other forms of television. Children's programming is expected to mean something for the development of the audience, indicating that external forces and social structures define and characterise the genre.

Examining the larger debates regarding children's television illustrates the pressures involved in making children's programmes before a need to reflect cultural identity can be considered. This helps to further contextualise the unique position of locally produced children's television in New Zealand, as there are a number of external forces involved in

${ }^{24}$ Messenger-Davies, Marie (2001). “Children's Television” in Glen Creeber (ed) The Television Genre Book, London: BFI Publishing, p.96. 
creating content. This section will examine some of the complex power relationships and definitions that are exerted over children and their programming.

Understanding the Audience

As illustrated in the review of literature on children's media use produced for the Broadcasting Standards Authority, debates about children have been preoccupied with the negative effects of media, especially the impact of violent content. ${ }^{25}$ Children are often viewed as innocent, passive sponges and television is considered an 'evil' influence that has the potential to corrupt the audience. This positions children as a special audience with particular needs and characteristics, predominantly the need to be provided with educational, positive programming free from "commercial exploitation or ideological manipulation". ${ }^{26}$ This has, as Jackson, Low, Gee, Butler and Hollings observe, resulted in a lack of engagement with children's opinions. ${ }^{27}$

British academic David Buckingham has raised questions about how childhood is defined and constructed in children's television research. ${ }^{28}$ As childhood is a common experience, those outside the audience are able to claim a sense of connection (and therefore protection) to childhood regardless of how the experience may have changed. This can result in greater involvement and a feeling of relevance and ownership for the different parties to these kinds of discussions.

Buckingham et al's examination of children's television in Britain explores the way that public broadcasters, policy makers, advocates and industry researchers attempt to define the child audience. In their research they observe that the history of children's broadcasting is built on the paternal notion of audiences in need of the moral and intellectual guidance provided by quality public programming. This debate has been engaged by Buckingham, Kline and Zanker in separate studies on the issue of which broadcasting system is able to best provide

25 Jackson, Sue, Low, Jason, Gee, Susan, Butler, Carly and Hollings, James (2007) Children's Media Use and Responses: a review of the literature, Wellington: Broadcasting Standards Authority, p.9.

26 Davies, Hannah, David Buckingham and Peter Kelly, (2000) "In the Worst Possible Taste: Children, Television and Cultural Value" in European Journal of Cultural Studies, Vol 3(1) pp.5-25

27 Jackson et al, p.9.

28 Buckingham, David, Davies, Hannah, Jones, Ken \& Kelley, Peter (1999). Children's Television in Britain, London:

British Film Institute p.2 
for and understand children and whether this is best enacted through structured guidance (public service) or children's tastes (commercial). ${ }^{29}$

\section{Culture versus Economics}

Buckingham et al and Kline place the British public service system in contrast to the commercial US - labelled by lobby groups cited in Buckingham as the "Worst Case Scenario". One of the harshest critics of the US system has been Kline:

"The marketplace will never inspire children with high ideals or positive images of the personality, provide stories which help them to adjust to life's tribulations or promote play activities that are most help to their maturation. Business interests trying to maximise profits cannot be expected to worry about cultural values or social objectives beyond the consumerist cultural vector that underwrites commercial media." 30

This further illustrates the concern that children are a special audience that need to be catered to in a particular way. They need to be inspired and instructed by television rather than simply given something that is enjoyable (and profitable). The expectation of cultural value produces an environment where children are not able to determine what they consider popular and entertaining in the same way as adults. 'Quality' programming for children is determined by those outside the audience.

Concerns such as Kline's have been echoed in legislation and lobbying for the 'protection' for children, for example the US Children's Television Act of 1990 where it is required that broadcasters provide a certain level of educational and social value. The US Congress concluded that the market had "not produced an adequate amount of children's educational and informational programming on commercial television and that government action was needed to increase the availability of such programming." This resulted in a federal guideline

${ }^{29}$ See Buckingham, David, Davies, Hannah, Jones, Ken and Kelley, Peter,(1999) Children's Television in Britain, London: British Film Institute; Kline, Stephen (1993) Out of the Garden: toys, TV, and children's culture in the age of marketing, London and New York: Verso; Zanker, Ruth (2001), What Now? : a New Zealand children's television production case study, $\mathrm{PhD}$ thesis, Waikato University.

30 Kline cited in Buckingham et al, 1999, p.47 
that each television station must air at least three hours a week of core education programming. ${ }^{31}$

The intervention into the US commercial environment with government policy illustrates that debates surrounding public service broadcasting provide a particularly relevant frame for a discussion of cultural identity and children's programming. Children and cultural identity represent two of the driving forces behind the ideology of public broadcasting - a commitment to nation-building and protection and consideration of vulnerable sections of society. ${ }^{32}$ In a commercial system these imperatives are considered secondary to producing a profit through maximising audience numbers through popular, entertainment programming. This demonstrates the peculiar broadcasting environment that local children's programming is expected to negotiate, and emphasises the extra pressure placed on New Zealand produced programming to be a site of public service values and cultural identity for children.

\section{Framing Cultural Identity}

At the heart of discussions about cultural identity is that it is a socially constructed concept. Identities acquire meaning through discourses and while they may appear 'natural' there is a significant amount of work that goes into constructing and maintaining them. ${ }^{33}$ This section will discuss debates and definitions of cultural identity to illustrate the complexities of a term that is considered such an integral part of creating children's content. The engagement with a sense of cultural identity is particularly important for children because, as Lealand has observed, they are the future audience for local content and establishing a strong local orientation early may encourage a stronger audience for local programming when they are older. ${ }^{34}$

${ }^{31}$ Federal Communications Commission (2007), FCC Fact Sheet: Children's Television Programming, available online at http://www.fcc.gov/Bureaus/Mass_Media/Factsheets/kidstv.txt, version current at 6/3/07.

${ }^{32}$ NZOA, (1999) Local Content and Diversity: Television in Ten Countries: A Report for NZOA, p.3.

${ }_{33} \mathrm{Liu}$, James H, McCreanor, Tim, McIntosh, Tracey and Teaiwa, Teresa (2005). "Introduction: Constructing New

Zealand Identities" in Liu, McCreanor, McIntosh and Teaiwa (eds) New Zealand Identities: Departures and Destinations, Wellington: Victoria University Press, p.14.

${ }^{34}$ Lealand, Geoff (2004), "Children's and Youth Television: The Most Important Genre?" in Roger Horrocks and Nick Perry (eds) (2004) Television in New Zealand: Programming the Nation, Melbourne: Oxford University Press, p.154. 
Cultural identity can be viewed, quite literally, as the feeling of belonging that an individual has in relation to a particular group or culture. This sense of belonging is also considered to give meaning to people's actions and experiences, and help them make sense of their lives. ${ }^{35}$ Barker observes: "the descriptions we hold of ourselves and with which we identify we may call cultural identity" ${ }^{36}$ This feeling of belonging does not occur naturally and needs to be reproduced daily. ${ }^{37}$

Cultural identity can be considered a "narrative, a story people tell about themselves in order to lend meaning to their social world". It is not fixed and is constantly changing and open to renegotiation..$^{38}$ The construction of cultural identity is best explained through Stuart Hall's argument that identities are constituted within rather than outside representation. ${ }^{39}$ Hall's reasoning impacts this research as this means that cultural identity is defined within the representations utilised in children's programmes. This indicates that programme makers engage with the concept in order to create these representations. As cultural identity is fluid and contextual the way that the creators understand and talk about cultural identity will impact on the kinds of representations present in the text. Definitions can also be found in how the audience discuss the texts and the representations utilised by creators in order to gain insight into what cultural identity may mean to them. This project will access these discourses through interviews with funders, producers and audiences in order to get a sense of how cultural identity is defined in relation to New Zealand produced children's programming.

Cultural identity and national identity are closely linked. National identity implies a more traditional and forced collective concept, while cultural identity allows for a slightly wider range of possibilities in an environment where negotiating identity has moved beyond geographical borders. The term 'cultural identity' in the New Zealand context is often used interchangeably with national or 'New Zealand' identity. Particularly as used in government

35 Tomlinson, p.7.

${ }^{36}$ Barker, Chris, (1999) Television, Globalization and Cultural Identities, Buckingham: Open University Press, p.68.

${ }^{37}$ Billig, Michael, (2004) Banal Nationalism, London, Sage, p.6.

38 Dockett, Sue and Cusack, Mella (2003), "Young children's views of Australia and Australians" in Childhood Education 79(6), p.364.

39 Hall, Stuart, (1997). "The Work of Representation", in Stuart Hall (ed). Representation: Cultural Representations and Signifying Practices, London: Sage, p.61. 
policy cultural identity alludes to a 'New Zealand culture' without excluding the different ethnic cultures that exist under this banner. In a document produced by the Ministry of Social Development cultural identity is described as allowing people to identify themselves as belonging to different cultures as well as considering themselves New Zealanders. ${ }^{40}$ The term is used to promote social well-being that will contribute to a positive national identity. Enabling different cultures to feel included will create a stronger sense of nationhood.

Discussions of national identity are useful for understanding the way that cultural identity is constructed and understood. Anthony Smith has discussed nationalism as a form of culture, "an ideology, a language, mythology, symbolism and consciousness - that has achieved a global resonance" 41 , indicating the close relationship between cultural and national identities. In his influential work Imagined Communities, Benedict Anderson proposes that the nation is in fact an imagined political community, argues that:

It [the nation] is imagined because the members of even the smallest nation will never know most of their fellow members, meet them, or even hear them, yet in the minds of each lives the image of their communion. ${ }^{42}$

This concept of the nation as being primarily imagined is imperative to understanding that national (and cultural) identity must be constantly reproduced and constructed to continue its existence. The idea that there is a cohesive force that bonds all members of a nation together is a challenging one, as it is ultimately unable to represent a group in its entirety, and can therefore only refer to a limited construction of a nation's communal bond.

\section{Cultural Identity in New Zealand}

The following section will discuss some of the representations of a New Zealand cultural identity that have been previously defined. This discussion provides some context for the

\footnotetext{
${ }^{40}$ Ministry of Social Development, "Cultural Identity" in The Social Report, available at

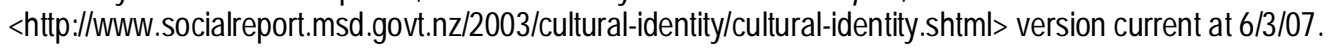
${ }_{41}$ Smith, Anthony (1991). National Identity London: Penguin, p.91.

${ }^{42}$ Anderson, Benedict (1991). Imagined Communities, Revised Edition, London:Verso, p.6.
} 
way that funders, producers and children may experience and understand cultural identity by deconstructing the style of 'New Zealandness' that has a historical relationship with New Zealand media and subsequently have a significant place in New Zealand cultural memory.

The use of well known representations of 'being a New Zealander' arguably impacts on the way that children are able to construct and understand their own sense of cultural identity. Claudia Bell has argued that the "self-generating version" of New Zealand's 'shared culture' has a particular relationship to creating a Pākehā identity, as the dominant culture is constantly struggling to define a collective identity. ${ }^{43}$ For Pākehā there is not the clarity of identity that is experienced by Māori, resulting in 'invention' being a recurrent presence in Pākehā society. ${ }^{44}$ Even with this lack of 'cultural clarity', however, Pākehā symbols dominate New Zealand identity formation. ${ }^{45}$ While Pākehā may have the loudest voice, it is also the most confused and ambiguous. Josephine Parlane aptly points out that "if the dominant group is culturally ambivalent, then so too is the New Zealand national culture subsumed under it." 46 This confusion has led to the perpetuation of 'identity myths', as the dominant identity (Pākehā) can still be regarded as relatively 'under construction', it requires constant affirmations of positive self-image. It is the need for such a positive identity that has spurred and informed 'identity myths', such as the nostalgic 'kiwi" childhood.

These 'identity myths' are evidence of a relationship to a nostalgic "New Zealand" childhood experience, contributing to an adult conceptualisation of children and their culture. This idea of being a "kiwi kid" is a prominent ideal through children's media and associated events, as well as being utilised to market certain products to children and their parents ("Kiwi Kids are Weetbix kids"). This connection is also apparent in the use of 'kiwiana'. Bell explains kiwiana as being "particular artefacts and images that have been adopted as symbols of nation. They are intended to invoke an instant, positive sense of New Zealand." ${ }^{37}$ Kiwiana is a visual or attitudinal connection to nostalgia, epitomised through the high profile of a wooden children's

${ }^{43}$ Parlane, Josephine (2003). "Street Legal: National Identity in a New Zealand Drama Series", MA Thesis, University of Auckland, p.94.

${ }^{44}$ Bell, 1996, p.26.

45 Parlane, p.95.

46 Parlane, p.95.

47 Bell, Claudia (2004). "Kiwiana Revisited" in Claudia Bell and Steve Mathewman (eds) Cultural Studies in Aotearoa New Zealand: Identity, Space and Place, Oxford: Oxford University Press, p.175. 
toy, the buzzy bee. Considering this relationship between childhood and nostalgia it is necessary to examine the impact that this connection can have on the representations of culture available to children.

Bell connects the resilient presence of 'kiwiana' and the term "kiwi" in New Zealand media with its ability to still be commodified for a modern child audience,

[T]oday's rapid turnover of must-have children's toys might lessen sentimental attachment, as even small children are today a significant consumer sector, constantly seeking novelty... As children engage far more closely with all media, with changing fashions, and with the inherent obsolescence of objects, media resuscitation will ensure which objects claim the firmest place in collective memory. ${ }^{48}$

The term 'kiwi' is also used as an exclusive form of national identity. Māori imagery and culture are especially used as distinguishing signifiers of identity rather than an engagement with, or reflection of, culture. A constant threat to this desired indigenity of the predominantly Pākehā 'kiwi' is Māori. A more detailed engagement with Māori culture could impact on the potential claim to indigenity of the 'kiwi' and its historical roots in New Zealand. Stephen Turner argues that this is why creating a national culture is largely the fixation of Pākehā, as there is a desire to establish a sense of place that Māori are assumed to gain from their cultural and historical ties to the land. ${ }^{49}$ There is very little research available regarding the way that Māori conceptualise forms of national culture or identity. In broadcasting particularly, the focus for Māori is to revitalise and maintain ties to Māori culture rather than being subsumed under the kind of imagery presented by Bell. A Māori Broadcasting Strategy released by Te Puni Kōkiri exemplifies this desire for revitalisation of culture and especially language:

${ }^{48}$ Bell, 2004, p.186

49 Turner, Stephen, (2007). "Inclusive Exclusion: Managing Identity for the Nation's Sake in Aotearoa/New Zealand", Arena, 28: p.89. 
The Māori language is the cornerstone of all that is Māori. Without it we are lessened as individuals and weakened as a nation...Our vision is for a time when Māori language can be seen and heard, and cherished by all New Zealanders. ${ }^{50}$

This vision is more specific than that given by NZOA, and the above focus has been a strong guide for the creation of Māori Television. There is a clear goal that by revitalising Māori language cultural ties for Māori will be strengthened and that its increased presence will foster a greater awareness from the wider New Zealand audience. This contrasts with the more outward projection of a national culture for Pākehā discussed by Turner and Bell. For Māori there is a more inward focus on being able to strengthen cultural ties within the Māori community and for this to be represented more accurately to the wider audience, rather than the appropriated shorthand that has been discussed earlier.

These discussions of the different ways that cultural identity has been utilised and understood in the New Zealand context help to illustrate the complexity of utilising such a highly mediated and constructed concept as cultural identity as a focus for programming. While this discussion only begins to deconstruct the difficult notion of a "New Zealand identity" it does open the term to be more cautiously considered than it currently appears to be within the broadcasting industry.

\section{Research Focus}

This chapter has framed the different debates surrounding the issue of cultural identity and children's programming, and the New Zealand broadcasting environment that aims to explicitly foster a sense of New Zealand identity. What is evident in these discussions is that children's programming has a number of different expectations placed on it. Programming made for children is expected to provide a meaningful and educational experience rather than simply being entertaining and engaging. In the New Zealand context pressure is placed on programming to provide children a reflection of cultural identity. Considering this demanding position for children's programming, there is a notable absence of discussions of

50 Te Puni Kokiri, Towards a Māori Broadcasting Strategy: Report of the Māori Broadcasting Advisory Committee, Sept 2000, available at <http://www.tpk.govt.nz/publications/docs/mbac\%20report\%20final30-09-001.pdf> version current at 6/3/08. pg. 3. 
how children's programming deals with the idea of cultural identity when it is so embedded into its financial creation and maintenance in New Zealand.

This thesis will address the way cultural identity is used and understood by funders, producers and the audience. Cultural identity is a social construction that exists within discourse and representations, therefore in order to deconstruct the idea of cultural identity and its role in children's programming, it is necessary to examine the different ways that it is conceptualised and understood by funders, producers and the audience. Deconstructing cultural identity through this funding, creation and reception relationship allows for differing definitions and understandings to be compared and contrasted and the complexity of an idea that is so integral to creating local children's content can be exposed.

To access these discourses interviews with funders and producers as well as an audience study with children were carried out. The following chapter will focus in more detail how this research has been designed and executed, in order to create a model that facilitates a discussion within an industry that is essentially dependent on the elusive concept of cultural identity. 


\section{Chapter Two - Methodology.}

The specific focus for this research is an examination of the discourses that creators and audiences of New Zealand children's programming use to give meaning to the genre and its relationship with cultural identity. The nature of this research lends itself to the use of discourse analysis, and, more specifically, an analysis based on qualitative interviews with creators and focus groups with children. More specific detail of the mechanics of these two phases of the research will be discussed later in the chapter. First, it is necessary to examine some influential studies to provide a methodological base and context for this research.

\section{Influential Studies}

While there is limited research in the area of children and cultural identity in New Zealand, overseas children's television has been the subject of considerable debate since television began. The majority of this work, however, has been concerned with the perceived effects that television has on children, their development and their social interaction. As Pecora, Murray and Wartella summarise, studies move from "media use to increasing emphasis on issues of physical and emotional harm, and changes in children's knowledge, attitudes, and behaviours". They go on to say that there are recurring studies about violence, sex, and advertising. ${ }^{51}$ Due to the large amount of primary research involved in this project and the preoccupation with media effects in research into children's television, a small number of influential studies have been chosen for their direct impact on the research methods for this work. They also provide an example of the style of research that has been carried out in the specific area of children and television.

One of the most challenging features of the research undertaken in this thesis is the combination of institutional analysis and audience research. There is not currently a precedent for incorporating both these forms of research regarding cultural identity in New Zealand. A range of previous studies have been influential for different sections of the project through their findings and chosen methodologies.

${ }^{51}$ Pecora, Norma, Murray, John, Wartella, Ellen (2006). Children and Television: 50 years of research, New Jersey: Lawrence Erlbaum, p.xvii 
The Children's Television Industry

Buckingham, Davies, Jones and Kelley in their study of the British television industry argue that children are "the least knowable of audiences"52, alluding to the difficulty of being able to understand children as an audience. Their research included over 40 interviews with people responsible for producing, distributing or regulating television for children, and they have outlined some of the key problems with industry-based audience research with children. While their study examines the British context, it provides relevant insight into how the industry understands itself (in the British context) as well as how the industry tries to understand their audience. Buckingham et al outline the difficulty of dealing with children due to the implicit psychological and ideological assumptions that arise from trying to define children as an audience. A consequence of this is that much of the broadcasters' knowledge of children is from their own subjective and anecdotal experiences, from their own children, friends, relatives and fan letters. ${ }^{53}$ Reasons for a lack of in-house research or the considerable secrecy surrounding research undertaken by creators stems from the competitive broadcasting environment, where commercial sensitivity and competition prevents research findings and other information from being shared. ${ }^{4}$

Ruth Zanker's ethnographic study into the production of What Now? provides the greatest precedence for research into the industrial practices and creative hurdles that children's producers face in New Zealand. By embedding herself in the production context of What Now? Zanker is able to examine competing cultural, economic and political discourses in "production talk". ${ }^{55}$ Her discussion of the "battles"56 over production agency in children's programming and examines the tension between creative visions for children and the stakeholders' differing constructions of childhood. Her case study deals specifically with the difficult creative and funding processes of getting an after-school programme, WNTV, to air and its subsequent commercial performance. The research is positioned as an analysis of

52 Buckingham et al, (1999) p.119

53 lbid p.117

${ }^{54}$ Ibid p.118.

55 Zanker, Ruth (2001), What Now?: A New Zealand's children's television production case study, PhD Thesis, Waikato University, p.2.

56 Ibid p.281. 
the processes and cultural power of the broadcasting environment of the late 1990s. This recognition and analysis of competing discourses provides a strong methodological platform for the industry research phase for this project. As her project focuses solely on the different interactions between funding bodies and daily production, it provides a model on how to approach and engage with the industry's creative process.

Zanker's research concluded during a time of significant change in the broadcasting environment with the succeeding restructuring of TVNZ and the creation of Māori Television. This research will use cultural identity as a lens to examine Zanker's observations and competing discourses in the children's broadcasting environment where more efforts have been made to prioritise children's content since the publication of Zanker's research. ${ }^{57}$ This project will also extend the discussion to include a consideration of the audience.

\section{Research with Children}

Focus group research is a useful tool to discuss issues and opinions with children. The focus group environment provides peer group support and recreates small group work that is often utilised in the classroom setting. ${ }^{58}$ Focus groups are also able to somewhat diffuse the potential power imbalance between the adult researcher and the child interviewee. There is also the potential for group dynamics and dominant personalities to influence the discussions within a group, and it is recommended that some form of activity is used to guide other group members into talking (in the case of this project this activity is watching television, as will be discussed later)..$^{59}$ Focus groups are recommended for children eight years old and above as they are more capable of meeting the conversational demands of this kind of research. 60

Audience studies that have direct relevance for this research include the work of Lealand and Zanker (2003) with their examination of children's media use in New Zealand. A study from Dockett and Cusack (2003) discussing Australian children's views of national identity

${ }^{57} \mathrm{Cf}$. The TVNZ Charter, NZOA's Children's programming strategy, MTS's provisions for children.

${ }^{58}$ Hennessey, Ellis and Heary, Caroline, "Exploring Children's Views through Focus Groups" in Sheila Green and Diane Hogan (eds) (2005) Researching Children's Experience: Methods and Approaches, London: Sage, p.237. 59 lbid 239

$60 \mathrm{lbid}$ 
and being 'Australian' demonstrates a discussion with children about how they understand and articulate issues of national culture and identity.

Lealand and Zanker conducted a series of focus groups in schools throughout New Zealand to investigate the access to and use of contemporary media- television, radio, computers and video games.61 A survey was used to gather information that could be examined in closer detail in later focus groups as well as indicate which children would be willing to participate in these groups. An extension of an earlier study in 1999, the focus of this study is gathering data on children's media use, media influence and media talk. There is evidence of high media usage and interest and a desire for freedom of access from children. ${ }^{62} \mathrm{~A}$ task allowing children to draw their dream bedroom illustrates that there is still a significant place for television in the desires of the audience, however there is a significant presence of interactive and highly branded spaces. ${ }^{63}$

Lealand and Zanker's study is designed to provide data about children's media use. There is not the engagement with the children's discussions of why they enjoy different types of media or how different media formats are privileged over others. The data does however create a strong platform for this research as it provides information about the role that television plays in New Zealand children's media diet. This establishes the potential impact media can have for a specifically New Zealand audience, as well as providing a methodological guide, and a base for discussion of more specific cultural or economic aspects of the relationship with media discussed by the participants.

Dockett and Cusack (2003) conducted interviews with primary school children in Australia investigating the way that the children discussed notions of being Australian, Australian-ness and national identity. ${ }^{64}$ They discovered that children in upper primary school had an increasingly complex understanding of nationality as they moved away from the definitions of

${ }^{61}$ Lealand, Geoff \& Zanker, Ruth (2003). "You'd have to change the world': Children and Media in New Zealand in the New Millennium" available online at

$<h$ ttp://www.netsafe.org.nz/Doc_Library/netsafepapers_lealandzanker_millennium.pdf> version current at 31/10/07 p.1.

62 Ibid p.9.

63 Ibid. pp.11-12

${ }^{64}$ Dockett, Sue \& Cusack, Mella (2003), "Young children's views of Australia and Australians” in Childhood Education $79(6)$, p.364. 
nationality as something shared by a group of people to the more abstract connection between people and the nation that they inhabit. ${ }^{65}$ Stereotypes did not prevail for these children, while there was some mimicry of language and clothing, they did not reproduce previously constructed tropes of an 'Australian'. The level of reflexivity with these slightly older children exhibited in this research indicates that there is an available level of understanding and potential for discussion about cultural identity for this project.

A study that provides a specific precedence for discussing New Zealand television directly with children is a report prepared for NZOA by Colmar Brunton which examined the attitudes of children and young people in relation to television programming and local content. This project is particularly influential for one of the major parties in the discussion of cultural identity, NZOA. The report states that the "data generated from this research used to refine policies aimed at fulfilling the obligations stated in NZOA's Children's strategy"66, as well as "assist in ongoing discussions with broadcasters and programme makers in such areas as developing workable guidelines for commercial elements in children's programmes." 67 This makes the report particularly relevant for its findings as well as its methods for talking to children about television.

A key finding of this report is that children aged 9-12 years are able to "fairly easily" identify New Zealand programmes and that they have "fairly high opinions" of them. However, the report is not entirely convincing in that New Zealand children "like seeing New Zealand things rather than overseas things". ${ }^{68}$ At different points in the report this more positive phrasing is replaced with children having "mixed opinions" of local content and that children feel that New Zealand "falls behind other countries".69 These statements are then surrounded by positive quotes from the participants that do not reflect these less supportive findings.

${ }^{65}$ Dockett \& Cusack, p.364.

66 "Kids Fail to Identify with NZ made TV" in The Dominion, Wellington, October 20, 2000, p.27.

$67 \mathrm{lbid}$

${ }^{68}$ Colmar Brunton, (2000), Children and Young People's Attitudes to TV programming and Local Content, Qualitative Research prepared for New Zealand On Air, available at <http://www.nzonair.govt.nz/files/about/C_YP_Attit.pdf> version current at $23 / 3 / 08$, p.8.

69 lbid p.23. 
The report also discovered that children have a desire to see their "aspirational self'70 on television, usually resulting in children watching programming aimed at an older audience. This aspirational self is not discussed in relation to local content, it is not considered if aspirational characters exist in only imported content or a mixture of imported and local. There is little engagement in the report with specifics about local content, while they do mention some characters from children's programming (Props Boy from What Now? and Spike the Penguin from Squirt, both now defunct ${ }^{71}$, it is not clear if they tried to direct the conversation towards particular New Zealand programmes, if any specific examples were alluded to, or if the children were guided towards local examples and how or why specific programmes meet particular children's needs and wants.

The above studies have provided an overview of similar research that has been conducted in the area of children's television. The following section will outline the programmes that will be used to examine cultural identity in this thesis before outlining the specific research design.

\section{The Programmes}

To access the discourses used by funders, producers and audiences regarding cultural identity, direct discussion is needed through interviews and focus groups. The frame for this discussion is four current children's programmes that are aimed at primary school aged children: Studio 2, Sticky TV, What Now?, and Pukana. These programmes have been selected as they are the only locally produced programmes that are available to children on a regular year-long basis, as opposed to drama series or more specialised talent programmes that have short seasons. These programmes also typify the traditional variety style of programming with sketches, competitions and audience interaction. The free-to-air networks are currently providing two locally produced weekday after-school programmes, TVNZ's Studio 2, a half hour show airing on TV2 at 4.30pm, and a recently launched extension of the brand into Saturday mornings, while TV3 offers Sticky TV airing 3.25pm-4.30pm. Weekend

70 Colmar Brunton p.27.

71 lbid pp.55-74. 
programmes What Now? and Pukana will also be discussed due to their historical presence and influence on the genre in New Zealand.

These programmes are all nestled between major US produced cartoon brands. Due to the nature of a daily schedule the cartoons and sitcoms themselves will change regularly, but the style of programming is generally adhered to. For example, a Japanese animated series or a Nickelodeon series will be replaced with similar products, presumably to ensure fluidity between programmes.

\section{Sticky TV}

TV3's Sticky TV is surrounded by an imported cartoon that is aimed at slightly younger viewers. The cartoons are generally American in style. Selections include: Go Diego Go (a spin-off show from Nickelodeon global hit Dora the Explorer). Aimed at a younger audience it is a bilingual (English and Spanish) cartoon about a boy who rescues animals with his family in the rainforest and Curious George, a cartoon based on the famous children's book series about a curious monkey named George. Sticky TV is followed by repeats of US sitcoms such as Everybody Loves Raymond or The Simpsons before the highly rated Australian soap Home and Away.

Sticky TV has traditionally adhered to the format of a wrap-around (interstitial) show for a series of imported cartoons and has previously contained as little as ten minutes of local content in the form of games and competitions. ${ }^{72}$ There has been a conscious move away from the funding of this wrap-around style of programming by NZOA. The 'wrap' format has come under criticism, with Zanker noting the formats inability to foster innovation and risktaking in the genre..$^{73}$ Sticky TV for 2007 has decreased the amount of imported animation and sectioned itself into two different parts. The first half hour contains the presenters doing brief activities in between a successful international programme brand such as Nickelodeon's Zoey 101 or Disney's Hannah Montana or The Suite Life of Zack and Cody. The second half

72 Lavranos, Eileen (2003) Children's Television Programming in New Zealand: Like the Kiwi an Endangered Species, Paper presented at ANZCA03 conference, Brisbane, July 2003.

73 Zanker, Ruth (1999) "Kumara Kai or the Big Mac Pak? Television for Six to 12-year-olds in New Zealand" in John Famsworth and lan Hutchison (eds) (2001) New Zealand Television: A Reader, Palmerston North: Dunmore Press, p.276. 
is entirely local content through the form of different segments based on a reality style format. There are physical and talent competitions, an agony aunt panel, as well as personal and bedroom makeovers.

\section{Studio 2}

TVNZ's Studio 2 is a half hour show that contains no imported animation. It is generally preceded by a major Japanese animation such as F-Zero, a cartoon based on a futuristic Nintendo game brand where the hero saves the world from aliens through drag racing his car with animation in the same style as Pokemon and Yu-Gi-Oh!. Cartoon Network brands are also popular with TVNZ, with cartoons such as Codename: Kids Next Door, based on five ten-year-olds who operate out of a tree-house against the tyranny of adults, and Ben 10 where a young boy finds a watch that gives him the ability to transform into a variety of alien life forms. Following Studio 2 is Nickelodeon ratings powerhouse Spongebob Squarepants, following the lives of a sponge and his best friend Patrick the pink starfish as they go about their lives on the lagoon floor at Bikini Bottom. At its peak in the US it was regularly appearing in the Nielsen Top 10 ratings and has spawned significant merchandising deals and a feature film.

Studio 2 itself is a half hour show that is filmed live (unlike Sticky TV) in the 'basement' of the TVNZ studios, giving the programme access to different celebrities and personalities that also work for TVNZ, with interviews and games with these personalities being a prominent feature of the show. They also utilise a 'talent show' feature through their 'Just Juice Super Squad' where children audition for one of the places on the squad (performer, sportsperson, brainbox, daredevil). The other key segment is 'I Spy', which involves the presenters and other guests from Studio 2 acting out a mystery that is played out over several months that the viewers are encouraged to solve at home.

\section{What Now?}

Premiering in 1981, What Now? has an almost institutional status in New Zealand's children programming. As the second longest running New Zealand produced show it occupies a particular place in the cultural memory of many New Zealanders. It is a two hour live format 
that currently airs Sunday mornings from 8-10am. Similar to Sticky TV it contains a half hour imported cartoon broken into segments and shown gradually throughout the show. What Now? also relies on sketch comedy and parodies popular programming such as Dancing with the Stars and America's Next Top Model as well as creating some unique sketches and characters. A unique feature to What Now? is the 'Spy Rider' segment. 'Spy Rider' has a designated presenter that travels to a different town in New Zealand each week and local children are invited to take part in games and competitions that make up a significant amount of the overall show (approximately half an hour).

\section{Pukana}

Pukana is the final show that will be examined in this project. Initially commissioned by TVWorks (TV3 and C4) in 1999 to appear on TV4 (now C4) as Tumeke, a youth Māori language show, it now airs on TV3 on Sunday mornings (in the same timeslot as What Now? on TV2) and on Māori Television (MTS) on Saturday afternoons. MTS offers a children's schedule from 4pm till 6pm on weekdays. Their schedule consists predominantly of cheap imported animation, mostly fairy tales and biblical stories that have been re-dubbed into $\mathrm{Te}$ Reo. While there is some original programming featured, these are weekly rather than daily like their counterparts. Pukana is similarly styled to the other programmes under examination, it is an hour-long live action show that involves skits, travelling to different schools and games and competitions. Pukana's key point of difference is that is made for those fluent in Te Reo and is designed to use Māori language and culture in a recognisable format.

\section{Programme Samples}

To provide the relevant background needed to engage both creators and the audience in a discussion about these programmes two samples were taken of each programme. Approximately four weeks worth of programming was sampled in two stages in March and August 2007. The purpose of the sample was to understand and relate to the programming discussed in the interviews. The first sample was viewed prior to interviews with producers and funders in order to identify programming style and recurring sketches and themes so 
that these could be used and discussed in interviews with producers. The second sample was viewed before the focus group research and clips for the focus groups were selected from both samples.

\section{Interviews}

Interviews with Creators (Funders, Commissioners and Producers)

Interviews were conducted with nine professionals involved in creating and funding children's programming in New Zealand. Where possible, the executive producer from each programme was interviewed as well key figures from some of the organisations involved in funding and commissioning the programmes. Human ethics approval from Victoria University of Wellington was granted prior to these interviews taking place. The interviewees were:

\section{Jane Wrightson, CEO, New Zealand On Air}

2.Emma Watkinson, Head of Entertainment programming, TV3

3.Janine Morrell, Executive producer, What Now?, owner of Whitebait productions

4.Emma Gribble, Co-producer, What Now?

5.Reuben Davidson, Co-producer, What Now?

6. Mary Phillips, Executive producer, Sticky TV

7. Nicole Hoey, Executive producer, Pukana, owner of Cinco Cine productions

8.Anna Allbury, Associate producer, Studio 2

\section{Pallas McTaggart, Associate producer, Studio 2}

The interviews were generally conducted one on one with the executive producer of each programme and in some cases with two co or associate producers. They were held at the production offices of each programme, or offices of NZOA or TV Works in the case of funders. The interviews varied in length between 40-90 minutes and were audio taped and transcribed. A conversational approach was achieved through the use of a topic list (see Appendix 1) rather than pre-determined questions in order to allow for conversation to flow naturally and new issues to be addressed and explored when they arose. 
The interviews were focussed on conceptualising cultural identity and what the concept means for each programme's content and creative processes. This was achieved through questioning about each programme's or network's overarching philosophy or "mission statement" and the role that cultural identity has in daily decision making. The interviews included a discussion of key objectives of the programme or organisation, how the audience is understood and interacted with, the importance of providing New Zealand produced programming, challenges and triumphs in programme creation, and ideas about future developments for the genre. These discussions were designed to indicate how issues of cultural identity play a role in the overall structure and maintenance of each programme or organisation.

\section{Interviews with Audiences}

In discussions that involve their media, children as an audience are often neglected. Children's programming is expected to mean something to the audience and provide a "valuable" (as defined by adults) experience. To be able to engage in a discussion of cultural identity for children it is necessary to explore how children understand the issue as it relates to their locally produced programming. Engaging in a discussion with the audience enables an examination of how the discourses presented by the producers are being received (if at all) by the audience. The aim of this study was not to generalise or speak for the audience as a whole, but rather to gain an insight into how children discuss cultural identity and their television programming.

This data was collected through focus group research with children aged 9-11 years old. Focus groups were chosen over other methods such as questionnaires or one on one interviews because it allowed the children to set the frame for the discussion, as Kitzinger and Barbour have argued:

"Focus groups are ideal for exploring people's experiences, opinions, wishes and concerns. The method is particularly useful for allowing participants to generate their own questions, 
frames and concepts and to pursue their own priorities on their own terms, in their own vocabulary."74

Enabling the children to use their own vocabulary and freely discuss and react to other members of the group is central to being able to analyse discourse as it is important to engage with the way that the children construct their own social realities through language.

The interviews were conducted at a primary school in Palmerston North. The children were selected from two senior classes (Years 5\&6), one mainstream and one from the school's bilingual unit where core subjects are taught in both English and Māori with up to $80 \%$ being delivered in te reo. Each child in the class was given an opportunity to participate and given information sheets about the project and consent forms for their parents to sign. 25 children were given consent to take part in the focus groups resulting in two groups of 5 or 6 children from each class. The specific make up of each group was the decision of the classroom teacher based on their interactions and experience with the personalities and social groups within their class. This was necessary to ensure the children were comfortable and would engage in discussion. Due to this selection process there was a higher number of female interviewees (17), with one group consisting entirely of girls. There was a high number of Māori children (11), making up just under half of the children sampled. There were 12 Pākehā children, one Pacific Island child and one child of Indian descent. The interviews lasted between an hour and an hour and a half each. All interviews were audio-taped and transcribed. Human ethics approval was granted by Victoria University of Wellington prior to these interviews taking place.

The focus groups were as follows:

(Names have been changed to ensure the anonymity of the participants)

${ }^{74}$ Barbour, Rosaline S \& Kitzinger, Jenny (1999). Developing Focus Group Research: Politics, Theory and Practice, London: Sage, p.5 


\begin{tabular}{|c|c|c|l|}
\hline \multicolumn{2}{|c|}{ Group 1 - Mainstream } & & \\
\hline Alias & Age & Gender & Ethnicity \\
\hline Petra & 11 & F & Māori \\
\hline Paris & 9 & F & $\begin{array}{l}\text { Pacific } \\
\text { Islander }\end{array}$ \\
\hline Nicole & 11 & F & Indian \\
\hline Hilary & 10 & F & Pākehā \\
\hline Quinn & 10 & M & Pākehā \\
\hline Mark & 9 & M & Pākehā \\
\hline Chris & 10 & M & Pākehā \\
\hline
\end{tabular}

\begin{tabular}{|l|l|l|l|}
\hline \multicolumn{2}{|c|}{ Group 2 - Mainstream } & & \\
\hline Alias & Age & Gender & Ethnicity \\
\hline Caine & 10 & M & Pākehā \\
\hline Kylie & 9 & F & Pākehā \\
\hline Cora & 10 & F & Pākehā \\
\hline Jenna & 9 & F & Pākehā \\
\hline Jon & 10 & M & Pākehā \\
\hline Brenda & 10 & F & Pākehā \\
\hline
\end{tabular}

\begin{tabular}{|c|c|c|c|}
\hline \multicolumn{2}{|c|}{ Group 3- Bilingual } & & \\
\hline Alias & Age & Gender & Ethnicity \\
\hline Aroha & 9 & F & Māori \\
\hline Jada & 10 & F & Māori \\
\hline Reka & 10 & F & Māori \\
\hline Dora & 10 & F & Pākehā \\
\hline James & 10 & M & Pākehā \\
\hline Tane & 10 & M & Māori \\
\hline
\end{tabular}

\begin{tabular}{|l|l|l|l|}
\hline \multicolumn{2}{|l|}{ Group 4 - Bilingual } & & \\
\hline Alias & Age & Gender & Ethnicity \\
\hline Jessica & 11 & $\mathrm{~F}$ & Māori \\
\hline Te Pura & 10 & $\mathrm{~F}$ & Māori \\
\hline Talia & 10 & $\mathrm{~F}$ & Māori \\
\hline Waireka & 10 & $\mathrm{~F}$ & Māori \\
\hline Arapera & 10 & $\mathrm{~F}$ & Māori \\
\hline Bea & 9 & $\mathrm{~F}$ & Māori \\
\hline
\end{tabular}


Like the interviews with creators a topic list (See Appendix 2) was used to maintain focus for the discussions while providing the flexibility to adapt to each group. The key objective of the interviews was to get the children to engage with what and why they liked or disliked certain programmes, any changes they might make given the opportunity, and comparisons between the different programmes. This was designed to examine if children actively engage with or consider any elements of cultural identity in their choices and reasoning. Structuring the interviews in this way allowed the children to not be confined to any specific ideas about cultural identity or forms of 'New Zealandness'. It also meant the children did not need to have any specific understanding of cultural identity or 'New Zealandness'.

The interviews were conducted away from the classroom setting to try to create a relaxed and conversational atmosphere. The research was conducted in a small resource room on the opposite side of the school to where the children are normally located. In order to make it feel less like a classroom we all sat on the floor in a circle. Generally this did create a relaxed and conversational atmosphere and it also allowed each child to be able to be seen by everyone in the room where they could be encouraged (or discouraged) by each other.

The groups were shown short clips (5-10 minutes) chosen from the sample of the four programmes under discussion. Segments were selected for their ability to exhibit patterns in style and approach as well as their representativeness of the programming philosophies that were outlined by the producers during interviews.

Due to their locality and affiliations Studio 2 are able to have a number of celebrity guests on their show. The clip selected from Studio 2 was an example of the format used when a celebrity guest is on the show, involving an interview and a challenge between the guest and presenter. During the interview viewers were able to send in questions for the guest, representative of the way that Studio 2 interact with their audience and encourage participation through technology. The selected clip for Sticky TV included a segment of presenter banter and competition over a daily fact and brain teaser and an example in the ' $U$ $\mathrm{R}$ Hot' series where the two makeover contestants are taken shopping for new clothes. The make over segment was chosen over the other segments because of the way that it clearly 
framed the focus on the participants and the presenters were there to guide and support those going through the make over, exhibiting Sticky TVs focus on making "kids the stars".

The What Now? clip included the presenters telling each other jokes and playing pranks on each other for their "Joke Day" theme as well as an instalment of 'New Zild's Next Top Model' a parody of America's Next Top Model, illustrating the 'fun and mess' What Now? prides itself on, through the interaction between the presenters (including Tamati on location with Spy Rider). Pukana included a regular segment where a young presenter and an older presenter compete in different activities (in this case learning magic tricks) with a punishment for the loser (eating wasabi) and a segment where popular music videos are recreated in te reo. The location of the competition segment in a shopping mall provides a visual representation of Pukana's philosophy of taking reo "to the streets", while the music video illustrates the interaction between language and popular (global) culture.

\section{Analysis}

As the mechanics of the research have now been outlined, this section will discuss the way that the data collected through this process has been analysed.

\section{Analysing the Transcripts}

Transcripts of the interviews with creators and the audience were analysed for recurring themes and concepts. ${ }^{75}$ For this kind of discourse analysis there is a focus on similarities and differences in how different people experience their worlds and the potential reasoning for these similarities and differences. ${ }^{76}$ Particular attention was paid to specialised vocabulary and the repetition of phrasing and ideas that relate to how cultural identity can be expressed and understood.

75 Rubin, Herbert J. and Irene S. (1995). Qualitative Interviewing: The Art of Hearing Data, London: Sage, pp. 230-1

76 Ibid p.235 
For the interviews with the creators of children's programming the transcripts were coded for the recurring themes and discourses regarding the role of cultural identity for their programme/organisation. Key recurring concepts that emerged were: how cultural identity is understood and defined within each programme, the motivations and challenges of creating children's programming, children's television in the larger New Zealand broadcasting environment, interaction with cultural identity that is a direct result of this environment, how the audience is understood and the connections between cultural identity and a nostalgic idea of "kiwi kids, the way that each interviewee understands or defines the idea of cultural identity, and their ability to express a "New Zealand way of life" for children.

Unlike the producers who are expected to have some knowledge of cultural identity due to its strong relationship to their programme through funding, children are unlikely to have had any interaction with what the concept may mean. Therefore the discussion for the children was framed to see how they engaged with their local programming and if cultural identity factored into this engagement. Therefore the focus groups transcripts were coded for the way that children made connections to cultural identity in their comparisons between the programmes. Key recurring concepts that emerged were the way that the programmes foster a sense of community, a desire to see other children on the programmes and the level of accessibility that a programme has for its audience, as well as how New Zealandness was understood and the kind of signifiers that let them know a programme was made in New Zealand.

\section{Discourse Analysis}

The underlying idea during the analysis was to understand the way that cultural identity is discussed and the impact this could have on the way that locally produced children's programming is created and received.

Discourse analysis engages with the idea that social texts do not merely reflect or mirror objects, events and categories that are already pre-existing, instead, they actively construct 
a version of those things. ${ }^{77}$ As articulated by Potter and Wetherell, "they do not just describe things; they do things." ${ }^{78}$ It is this idea of construction versus reflection that is particularly relevant for this project. Not only is cultural identity itself an idea that is constructed, but looking at the NZOA guidelines, it is a concept that is expected to be "reflected" in children's television texts. The recognition that there are larger societal and contextual issues at work in discussions about children's television provides a platform to deconstruct cultural identity and provides the possibility for contradictions and definitions of what cultural identity could mean and how it is best represented in children's programming.

While not being a clear cut, step by step method, discourse analysis is a theoretical foundation that considers people use language to construct versions of the social world. This is exhibited by Potter and Wetherell's argument that the self is "inextricably dependent on the linguistic practices used in everyday life to make sense of our own and others' actions."79 The way that people represent themselves and understand others is through language, itself a social construction.

An understanding of contextual issues allows for underlying attitudes and reasoning behind certain articulations and discussions to be better understood. Discourse analysts are concerned with "construction and function"80: how is discourse put together (context), and what is gained by this construction. In order to understand the context of why cultural identity might be conceived and articulated in a particular way there are a series of issues that need to be considered: the possible historical or political basis for the articulation, the potential reasoning for the need to perpetuate or add to this articulation (discourse), and the significance it could have for the others involved in the creator/audience relationship.

The ideas of discourse analysis outlined above provide the foundation for examining what cultural identity means and how it is understood regarding children's television in New Zealand. The following chapters will discuss the results of the institutional and audience

\footnotetext{
77 Potter, Jonathan and Wetherell, Margaret, (1987). Discourse and Social Psychology: Beyond Attitudes and Behaviour, London: Sage Publications, p.6.

78 lbid

79 lbid p.95

$80 \mathrm{lbid}$ p.160
} 
studies in more detail. Chapters three and four concentrate on examining the way that cultural identity is articulated in each of the studies, this is then compared and contrasted in the final chapter of this project in order to create a dialogue between funders, producers and the audience regarding cultural identity and its impact on locally produced children's programming. 


\section{Chapter Three - Industry Interviews}

Creators of local children's programming demonstrate a level of discomfort with the programme makers being actively involved in constructing cultural identity. There is a strong preference for considering programmes as a vehicle of 'reflection' for an actively involved child audience. The use of traditional New Zealand imagery, however, as well as a nostalgic discourse of what it means to be a "kiwi kid" opens up a discussion of inherent power structures between the creators and their audience that makes this 'reflection' difficult.

While 'cultural identity' itself was not considered the most 'useful' of concepts by the programme makers, the presence of similar ideas in general discussions of each programme illustrate that it is a significant tool in the construction (or 'reflection') of the audience and their interests. Discussion around three key areas became sites of how programme makers and funders interact with this idea. The following analysis will centre on discussions of how interviewees understand New Zealand children as an audience, children's television as a genre in New Zealand, and the way that they are able to 'reflect' and utilise a sense of New Zealand 'culture'.

Outlined below is a brief introduction of each programme's philosophy or mission statement to provide a broader context within which to place discourses involving New Zealand children and cultural identity. This will outline the programmes and their particular focus before moving into a more specific analysis of the key themes being utilised by the producers and commissioners in relation to the role of cultural identity for the genre.

\section{What Now?}

The producers of What Now? consider their programme as "early morning madness with kids at its centre and family at its heart". It has what executive producer Janine Morell-Gunn describes as a different "mantra" each year. This is the foundation of their programme and is embedded into their decision making process and acts as their internal way of guiding decisions and ideas into a cohesive overall theme for each year. As Morell-Gunn explains: 
Most years we have a mantra at WN... this year it's 'through kids eyes' and everything is, I'm always saying "shoot lower, get down, look through their eyes, see it through their point of view", go to Rotorua, sure, incredibly touristy but we do a story on the boy that's got a job and gets paid 20 bucks every time he turns up to do his haka, but it's through his experiences, so you know, we really do try to connect in with kids and through their eyes.

\section{Studio 2}

Providing interactivity is a core part of Studio 2's programming focus. When associate producers Pallas McTaggart and Anna Allbury were asked to explain the kind of show that they try to create, this was the first element mentioned.

$A A:[l]$ t's a show that the kids own, what kind of show is it? It's interactive, that's one of our biggest things because for kids to own the shows they need to be able to interact and to be able to tell us what they want and be on screen, so there's the interaction and for us it's also about getting around the country as much as financially and logistically possible.

PM: Yeah, it's kids on screen and off screen.

As with What Now?, Studio 2 considers its role to be a vehicle for their audience's own agenda. However while What Now? represents its audience through showcasing talent and interacting with subjects from the point of view of their audience, Studio 2 considers itself a direct interactive platform that enables "kids to own the shows" and interact with content themselves. There is an implication here of constant and direct contact and consultation with the audience, who are in control of the content. 
Sticky TV

Echoing Studio 2's concept of "kids own the show", Sticky TV touts their focus as being "making kids the stars". Mary Phillips the executive producer describes this as:

You always put the kids first and go 'ok well what can I do that's going to work for them', it's like the presenters, that's fine but the viewers are far more important and they make them the stars, yeah I think that's what we try and do, and give kids a voice.

Sticky TVs philosophy reiterates the kind of statements made by the other producers in that programmes are considered a platform for children to display their talents and ideas. This suggests that for all three programmes the audience is the priority in their content decisions and that the agenda for the programme is set by the viewer rather than the presenters or programme makers.

\section{Pukana}

Pukana is the only programme to define itself in different terms and have a more specific and tangible focus for their content. Nicole Hoey outlines the premise of the programme as follows:

The thing about Pukana is taking reo to the streets, taking Māori language to the streets, we took it out of the environment of just the Marae or just the Kura and we have it being used on the street.

Because Pukana is designed to cater for a niche audience rather than the very broad target audience the other three programmes are all trying to attract, the language, rather than children themselves, becomes the driving force in terms of content. Pukana bases its appeal on being a being a site of Māori language, rather than only being defined by its intended audience. 


\section{Understanding Children as an Audience}

The boundaries that are placed on programming by outside forces such as NZOA (funding) and the Broadcasting Standards Authority (appropriate content) indicates that notions of "reflection" and "participation" require further deconstruction. The way that each programme is expected to conceptualise and construct its material as a result of these expectations raises issues of programme content not being a natural process of 'reflection' but a more considered series of calculated decisions. It is the way that these decisions are made in regards to creating a sense of cultural identity and the way that this is conceptualised through their programming that is the driving focus of these interviews. This section will explore how programme makers define their audience in order to 'reflect' them and examine some of the conflicts involved with producing content that caters for the different pressures and expectations of children's programming.

The almost reluctant sense of authorship expressed by the majority of the producers illustrates the difficult position that makers of children's television occupy. There is a strong awareness that they are not children, and they are therefore quick to place the ownership of the programmes back into the hands of the audience. The constant need to reaffirm an empathy and connection to the target audience is more pronounced than in other forms of television because the producers are so clearly in the situation of appealing to an audience that they are not actually a part of. This recurring issue, expressed through the rhetoric of "reflecting kids worlds" further complicates the inherent power relationships between producer/viewer, adult/child and imported/local. Such mantras and philosophies only further emphasise the innate disconnection between the adult programme makers and their nonadult audience.

In order to "reflect kid's worlds" it is necessary to have an understanding of or connection to the children as audience. As the programme philosophies demonstrate, there is a clear invocation of the audience as a driving force behind content. Given this strong focus on providing programming that is "reflecting their audience's worlds" or seeing the world "through their eyes", the way that programme makers conceptualise their audience and their 
audience's interests has a direct relationship to content and consequently a direct relationship with the way that each programme interacts with cultural identity. Discussions of the way that the producers understand their audience focussed on the type of content that attracts children, the way that producers gather information and interact with their audience, and the way that the audience is able to interact with the programme.

The impression given through the programming strategies is that producers see the audience as children first, and all other cultural factors are secondary. There is also an assumption that this is the way that their audience will identify themselves. Janine MorellGunn (What Now?) observed that "kids will stop dead in their tracks to see another child on screen". This is echoed by Mary Phillips (Sticky TV) when she describes the kind of programming that children want:

Humour, totally, humour and voyeuristic, it's that whole reality thing that's what it's about, how other kids live, what they do, what they wear, just that line into teenage that we all knew and loved ourselves.

Providing the audience with the opportunity to see other children, however, is a challenge. For children to see their own realities on screen while also gaining insight into those of other children requires considering a wide range of ages and lifestyles. Reuben Davidson of What Now? describes this task as challenging but also a large part of the appeal of working in the genre:

[l]t's that thing of keeping it alive and keeping it really funny and reaching all those different kids and trying to offer something in the two hours and offer something to any kid in New Zealand who's watching it because, you know, every kid is going to have a different interest, there might be some watching it in an apartment in Auckland and there might be one watching it in a back-block farm where it's their only link to other kids in New Zealand, so it's that trying to cater for absolutely everybody which makes it so exciting on a Sunday morning for two hours because 
you cram so much into and try and have so much variety, it's always fun, which is good.

This need to cater to absolutely everybody is tied to an awareness of the variety of backgrounds of their audience. Here it is being linked with a difference in geographical backgrounds and into a traditional trope associated with New Zealand identity, an urban/rural divide. The use of such a trope also suggests an element of homogeneity in the way that the identities of the audience are being subsumed under larger traditional (and usually adult) discourses of New Zealand identity. Also noticeable here is the fact that cultural identity is not referred to directly as being part of the appeal for children, providing an example of the way that cultural identity seems to be assumed or inherent in the producers' considerations of the audience.

While there is an awareness of the variety of backgrounds that their audience come from and a concern to reflect those backgrounds, there is at the same time a propensity to elide the differences, again indicating homogeneity, within the audience by appealing to them as a larger community of children. Using humour and parody where children are able to get the better of adults is able to connect with children at this larger level. Nicole Hoey (Pukana) provides an example:

Kids love to see adults slip on a banana skin and fall over, they laugh, and it's that type of human comedy.

\section{Educational Programming}

This 'human comedy' is also used to convey the different educational messages that are an important aspect of the majority of the programmes. This places the programme makers in the position of educators and the audience being in need of education, a key external expectation of children's programming is that it is a valuable (educational) experience for children. 
Children needing education creates a dynamic between the notions 'reflection' and 'creation'. Education and learning are a central part of children's everyday experience. Providing educational content further demonstrates the divide between creators and their audience. This arguably makes the ability to purely 'reflect' children's realities more complex by giving programme makers an authoritative role through deciding what kind of content has educational value for the audience. Aside from Studio 2, each programme considered a core part of their function providing some kind of educative role:

I talk to a lot of teachers, and work out exactly what's happening at schools and what they're teaching at schools and what the culture is at school, so we're actually alongside what's happening at schools and what they're teaching and the values... Although the show is really fun it's got absolutely core educational, fundamental things happening."

Mary Phillips (Sticky TV)

[B]ecause it's a Sunday morning we don't want it to be a classroom as such, but if it's a classroom, it's a good, fun classroom. So using the What Now? presenters and using the comedic strengths of the What Now brand to just get really simple messages out to kids as well. Like the things with not smoking and healthy eating as we mentioned earlier.

Reuben Davidson (What Now?)

We have a dual role, we play an educational role, we also play a role in getting Māori language onto television screens and in a way that no other programmes do, we use satire, we do a lot of satire in the show... we parody our own people in a way that kids like and understand, we look at tikanga and how it applies to the modern world and we have a parody section on that and we take a lot whakatauki, which is a lot of the old Māori sayings and bring them into usage here in modern English.

Nicole Hoey (Pukana) 
This educational role also extends to social issues, as seen in the "Howzit" segment for Sticky TV, the agony aunt format includes teenagers helping answer problems and questions that viewers send in. Mary Phillips (Sticky TV) explains here that this guidance is an important part of being able to engage with and reflect the audience:

Kids see themselves and go 'oh gosh that happened to me, my parents got divorced and this is the way someone else handled it'. A lot of the middle part of the show is the question and answer thing [Howzit] and we just got this research the other day from What's Up? Helpline and when we go on, the phone calls triple.

The power relationship becomes problematic when juxtaposed with the initial views of the programme makers, where they are quick to cite children as the drivers of content. While children may themselves thrive on and desire interesting and educational elements in their programming, there is still a conflict in how programme makers can accurately 'reflect' children's worlds when they are required to set an educational agenda in their programming. The ideas and choices of the programme makers themselves are not under question here nor are the wider issues of providing educational content to children; the crux of this discussion is the way that programme makers are caught in conflicting and complex ideas and rhetoric regarding their own self definition and the relationship constructed with their audience. This difficult self-definition has repercussions for "reflecting" cultural identity, as will be discussed further later in this chapter.

\section{Audience Interaction}

The producers' claims of 'reflection' are helped by the level of interactivity that children can have with their programmes. This section will outline the role of producer initiated interaction and child initiated interaction and their impact on content and the way that programme makers understand their audience.

Producer initiated interaction refers to programme makers utilising focus groups and other research methods to test their own programmes and to determine what the audience is 
currently interested in. As Buckingham et al have observed, much of the interaction between creators and the audience is through competitions and fan mail, only giving programme makers access to those who are already fans of the show. ${ }^{81}$ For the majority of the interviewees in this research this form of interaction was very important. Sticky TV and What Now? however, also conduct research in schools to enable them to be more involved with what is popular and appealing to the audience.

I think with What Now?, it's got to keep fresh because it's been going for so long and you can't rest on your laurels and we have a very discerning audience which is why we research and once a term we head out to schools with different deciles and different cities and towns to see what they're laughing at and to see what they watch and what they don't watch and it's really interesting observing them, we often film them watching TV or we do questionnaires.

$$
\text { Janine Morell-Gunn (What Now?) }
$$

We've got a group of kids there's probably about 20 that we have and we keep changing them, they're from all over Auckland, and we send people out to talk to them and to talk to them about the shows they've seen, what we could be doing coming up, what the next season could involve, what their lives are like and what they want to know more about.

Mary Phillips (Sticky TV)

This level of interaction indicates a dialogue that is uncommon with other forms of television where the majority of audience response is gathered through ratings data. However, this also further illustrates the distance between makers of children's television and their audience as opposed to more adult forms of programming. The "limited life experience" of the audience can make them more difficult to cater for, and programme makers need to be interactive with their audience. The constant need to 'keep up' and stay "fresh" reinforces the difference kind of "world" that the audience inhabits.

81 Buckingham et al 1999, pp.117-8. 
Child initiated interaction refers to the interaction that the child have with the specific programme. Janine Morell-Gunn (What Now?) mentioned that children often send in different gifts with their letters. When the programme receives a lot of the same kind of item, they know that it is something they can work into their show through a competition or feature segment. Studio 2 also has a strong reliance on fan interaction, which makes up a key part of their content through reading live texts, email and internet chats. Studio 2 prefers this method of interaction to connect with their audience rather than setting up the kind of research utilised by Sticky TV and What Now?

The ability of programme makers to be interactive with their audience is regarded as crucial for maintaining a connection to and interest from the audience. Anna Allbury from Studio 2 explains the role that providing content for different media platforms and utilising different methods of communication has for their programme content:

Our executive producer lan Taylor one of his big things is going where the kids are at, and there's been a lot of research done that shows that these days that kids are just multi taskers, they're on their cell phones and on the computer and watching TV at the same time and a lot of kids these days, their computer is their most valuable media delivery system, so for us that's where we're going.

These comments illustrate a conceptualisation of Studio 2's audience that has a very direct impact on programme content and focus. Viewing the audience as multi-taskers and aiming to cater for this by including different technologies as part of the show indicates an expectation that the audience want to directly connect to the programme. This connection is seemingly different from a traditional fan-programme relationship where the ability to affect programme content is minimal, and the fan community is not used within the world of the programme. Here, technology acts as a tool for participation in and membership of a particular community. This is seen in the descriptions of "The Hub", Studio 2's website:

Our online website this year The-Hub.tv, you register as a member and there's something like 20,000 members on there now and they have their own profile page and they interact with the presenters and guests on the show and in the hub- 
talk section they can upload things, so that's another way that they're actively involved in the show...that's huge for us to make sure there's plenty of young people participating in the show so we're not just making it for them, they're participating with us and making TV for us as well, that's something else that the hub is there for.

\section{Pallas McTaggart (Studio 2)}

What is of particular interest here is the way that this interactivity acts as a proud point of difference between local and imported content in the New Zealand schedule,

The Disney channel, I mean the kids can't participate, I mean they can view them and they're international shows and they're very popular but they don't reflect New Zealand and New Zealand kids can't participate in them they can only view them, so there's only one side to them.

\section{Pallas McTaggart (Studio 2)}

The ability to reflect New Zealand is used here as an attractive quality for children's programming, and sets it apart from imported competition. This interaction as well as more specificities of the genre in New Zealand will be explored in the following section.

\section{Children's Television in New Zealand}

After evaluating the way that programme makers understand and interact with their audience and the different expectations placed on children's programming, the following section will examine the way in which the New Zealand environment places further pressure on the ability of producers to 'reflect' their audience. The way that that programme makers interact with the broadcasting environment provides insight into the perceived role that their programmes are expected to play in their audience's lives while meeting the different demands of NZOA and the respective networks. 


\section{Funding}

Funding is considered the biggest challenge and barrier to making children's programmes. The limited amount of money available for this area and the almost complete reliance on NZOA funding due to the limited advertising revenue available to networks for these kinds of programmes leaves programme makers in a difficult financial situation. As funding comes with the expectation of reflecting cultural identity, this is potentially an issue for how programmes are able to engage with the cultural identity within their budget constraints.

The budget becomes a particular issue in regards to paying for the people who help produce the programme. Reuben Davidson and Emma Gribble (What Now?) put this into perspective when they discuss the kinds of decisions that the funding causes,

EG: Sticking to the budget is huge as well, because what happens is that our budget is the same every year but everything changes, you've got a team that is getting so much better in skills and you want to pay them more and you want to retain them because they're so great and What Now? has been known as a platform for so many people to learn and then go on to something else and because we want to do so much creatively it's quite tight with the actual money to pay the people, but we've got some amazing people and we try and keep to budget but pay what you want to pay people. Yeah, the budget's hard.

RD: Nobody says 'oh this year we're going to charge you this much less than what we did last year' everybody wants more every year, but that's just how the world works.

EG: But we don't get any more so that's always a real issues, because if you're going to give people more you have to take something away from creativity.

These comments demonstrate the impact of stringent and set annual funding amounts that do not allow movement for the growth and expansion of their programme brands. This set 
amount of funding also impacts on producers' abilities to provide the audience with the level of interactivity through multi-platform delivery discussed earlier. Nicole Hoey considers this one of the main challenges currently facing Pukana:

Money, we've never got enough money, children's programmes are always under funded, you've always got to think of ideas and fit them into your budget [and with] technology changing we've had to develop online activities and that's been a big challenge for us.

Hoey raises the difficulty of providing new technologies with limited funds, and the need to 'fit' ideas into the budget. This was a recurring issue amongst all the producers. But while funding on the one hand is considered a dampener for creativity, on the other hand it can also act as a catalyst. While limited funds mean that certain ideas are not able to come to fruition, there is also the challenge to think creatively in order to stretch the money that is available. Anna Allbury from Studio 2 hints at this when she says:

I mean you can have this amazing idea and that'd be fantastic but there's just not enough money. You see some of the budgets that overseas kids shows have and they're like 'wow, imagine what we could do with that, we could really have all these amazing ideas come to life but yeah I guess it's making the ideas that you have work with the money available.

As a way of opening out these financial restrictions and gaining insight into the kind of content that could be produced if this barrier is removed, each producer was asked about the changes that they would make to their specific programmes as well as children's television in New Zealand generally. Each programme indicated that, if given the opportunity, they would make technical improvements rather than change content or style. This would seem to indicate a level of satisfaction with the current style and focus of programming. Studio 2 would also improve their accessibility to their audience by travelling around the country as they currently spend their resources enabling their audience to reach them through communication technologies. 
We could have more participation, we'd have a bigger studio, a better studio, we'd have a studio audience, we have a very small studio here at TVNZ so it's not available for children to come to, we have a few at a time but not many, the possibilities are endless, there's been many an idea that's been had to let go for that very reason. Travel, more kids could participate.

Pallas McTaggart (Studio 2)

These suggested improvements illustrate a confidence in the current programming style and the driving concepts level of satisfaction with their current focus, strengthening the definitions and ideals that the programme makers have created for themselves. Both What Now? and Pukana also had different children's projects (including drama and indigenous animation) that they hoped to be able to make in the future. These other projects are ultimately held up by issues related to funding and the broadcasting environment, as Janine Morell-Gunn (What Now?) explains:

I do think there isn't enough diversity in children's shows and I'm a big advocate and campaigner for this, that children deserve the same range of programming that adults have, so where are the children's documentaries? Where's the sports show? There's a whole lot of things, the talent and variety show for kids, a gameshow for children, I want to make a quiz show next year. Then it becomes 'ok Janine if you're going to do this what aren't you going to do' because it's this or that.

The lack of diversity available for children's programming and the questions raised above are indicative of the way that children's television fits in an environment where locally produced material is at a disadvantage. What is important to note here is that in their discussion of funding there is little reference to cultural identity. This indicates that while a requirement to gain funding, cultural identity is not as actively considered in the daily decision making of the producers. 
NZOA funding is to ensure children's programming as a genre survives, as well as provide expression of cultural identity for children. As CEO of NZOA Jane Wrightson explains,

[C]hildren's programming is definitely public service related because it is not particularly commercial, broadcasters will tell you they probably lose money on it these days, not the least of which is because of the sensitivity around advertising in programmes and because pre-school programmes have literally no advertising at all so it's a classic area where support from public funding is required.

Children's television being "public service related" places further expectations on the genre to be more than simply 'reflective'. It is required to be of value for the audience and inform and educate in a way that commercial programming will not.

Funding from NZOA can only be granted after broadcaster support has been assured. There is a potential tension here for producers as the broadcasters have commercial goals. This makes the ability to create and maintain a programme that is able to satisfy both parties and the audience more complicated. Children's programming is in a particularly unique position as it is almost entirely reliant on NZOA funding for its survival. Janine Morell-Gunn (What Now?) explains how to deal with the tension involved in the broadcaster, funder, producer triangle:

Sometimes producers are known to almost write two documents, the one that gets the broadcaster onside, which is all entertaining and sexy and savvy and the one that gets NZOA onside which is all about New Zealand culture and identity, generally you try to see the benefits of both, and usually TVNZ Children's are looking for audience winning, and that's what they're about, they are in the ratings game to be commercially viable... They each have a different set of criteria that they want you to meet and you as a programme maker have to be cognisant of that, the key thing in all of is that the audience doesn't get lost. We have to make sure that kids still want to watch, and generally for a show like WN it's quite a nice balance. 
Writing two proposals in order to negotiate the different demands of NZOA and the networks illustrates the almost split personality expected of this kind of programming from its inception. Jane Wrightson (NZOA) and Emma Watkinson (Head of Entertainment Programming, TV3) illustrate the slightly different focus and expectations placed on the genre.

JW: With all our funding, it has to reflect and develop New Zealand identity and culture. That is the prime requirement of us under the Broadcasting Act, that's a sliding scale if you like depending on how much funding is required of us. So if we are asked to $100 \%$ fund a preschool programme, we will require it to be authentically New Zealand and reflect a range and diversity of New Zealand voices and views and cultures...You can't make rules like this as a policy, because you need to, I think, respond to the creative brief each time and then work back, but the first question is, how does it relate to, reflect and develop NZ identity and culture and if it doesn't at all then the funding will not flow.

EW: I always ask them [potential producers] to look at Sticky TV... I want to have something that is quite different so that we have something that provides variety... and freshness so that it's new so that it offers people something new and fresh and a reason to come in and watch it, and it needs to reflect New Zealand and New Zealanders of course, New Zealand kids and what they're interested in. And that may be a really broad thing for kids I mean it needs to be representative of us as a nation and our culture but it needs to have an appeal to kids as the main thing, a broad appeal to kids as well...If it's [a programme proposal] something different, something that we haven't necessarily seen before...yet children can take a really active role in it, but it's got new media in it, that thing that children and everybody else in the world is latching onto, which is interactivity with the text element to it.

While both the television network and NZOA insist on the need to reflect New Zealand in children's programming, the discussions of this issue are framed quite differently. For NZOA, 
the driving force for providing funding for a programme is the ability to "reflect and develop" a sense of New Zealand identity and culture and the level of funding a programme receives is entirely contingent on the degree to which the programme is able to fulfil this. While TV3 share a focus on the reflection of New Zealand, this appears to be a required part of the background rather than part what makes a programme attractive. For TV3 the ability to appeal to a broad audience through fresh content and style takes precedence.

These two discourses, while not necessarily conflicting, demonstrate the difficulty of creating programming that is able to satisfy both public service and commercial expectations, as well maintaining an audience. This difficulty results in minimal risk taking and reliance on variety formats which as they meet the differing expectations and within the funds available. Emma Watkinson's comments reveal a desire for innovation, however, she also illustrates the conflict between innovation and a reliance on formula when she states that TV3 want proposals that on the one hand show something "that's really new and different" but that producers are directed to Sticky TV as an illustration of how TV3 like potential programmes to be pitched.

TV3 are known as a commercial broadcaster and there is an expectation that TVNZ occupies the more public service role in New Zealand broadcasting. This arguably means a greater sense of importance placed on creating children's programming, particularly after the introduction of the TVNZ Charter which requires a commitment on TVNZ's behalf to provide high quality children's material. However, Janine Morell-Gunn (What Now?) explains that there has been little impact on children's programming after the introduction of the Charter and the provision of extra funding:

No, none, I thought the charter might open up more opportunities to make children's programmes but I haven't seen that, there might have been some initiatives, but not really no, and in terms of editorial policies or children's strategy, there's been nothing under the Charter, it hasn't really filtered down into children's, people are really cynical of it and how that has assisted the audience. 
Local diversity is a key issue in children's schedules. The audience has a range of programming available to them across the major free-to-air networks and the dedicated Sky TV channels Nickelodeon, Disney and Cartoon Network. This imported content is designed for the audience in the programmes' domestic markets. Jane Wrightson articulates this issue when explaining the importance of providing locally produced programming for New Zealand children:

From a cultural perspective it [locally produced programming] is critical, we know that in all other genres including children's there is a surfeit of foreign content available at very cheap prices, in other words considerably less than the cost of making it, because we're an English speaking country broadcasters have no shortage of material to choose from America, Great Britain and Australia, and indeed English dubbed material from Asia, particularly animation, so if you're going to create a broadcast landscape for children that reflects their own country and their own culture the only way you can do that is of course through supporting local programmes.

While this kind of discourse demonstrates a need to support local programmes this becomes difficult when the audience exists in an environment dominated by global (largely American) popular culture trends that they are exposed to through their media usage. This difficult relationship between creating culturally relevant children's television and reflecting children's interests (that are arguably influenced by the high levels of foreign content) is explained and exemplified by Jane Wrightson (NZOA):

It's very different, what we think is good for children, which is what programme makers argue vociferously, what we think is good for kids with our high-faluting statutory responsibilities and 'it will be good for you' kind of notions may absolutely send children running from the room screaming. Which means we're not spending money well. And we are not delivering them what they want so it's a very careful balancing of the high-faluting cultural imperatives with the delivery of product that they are actually going to want to use. 


\section{Utilising Global Trends}

The way that children's programmes incorporate and interact with pop culture is indicative of the difficult balance required of children's television in order to retain the attention of an audience that is exposed to high levels of imported product. This balance differs for each programme and the way that programme makers approach imported products varies:

We try and ask things through kids eyes so we want to be where kids are at but there is some editorial license that goes on, for example we don't want to promote movies that, it's very difficult with movies, Harry Potter this latest Harry Potter is an $M$, that is outside our target audience, $P G$ is fine and things but a lot of stuff is not appropriate, try and find a music video without swearing and without gratuitous sex, it's bloody hard.

\section{Janine Morell-Gunn (What Now?)}

For instance you know High School Musical was the big thing... I think we can take it and go yeah that's interesting and springboard into something here, like we might go, send us in a video of you singing, or let's make a musical of our own about Sticky TV, which we do, the kids write lyrics for songs and Drew who's really musical writes the songs and yeah we would probably use it as a springboard rather than something to embrace.

$$
\text { Mary Phillips (Sticky TV) }
$$

We've got to cross the line in that area and continue to push the boundaries in it because ultimately if our language is going to survive we've got to do that, within bounds of respect as well, obviously you can cross the line too far and you're dead in the water. But there's other crimes that are worse...I think that we've got one part of our show that is a rap so we've had to acknowledge popular culture, we use krumping, we use hip hop, we embrace it and try and put something from our 
world into there as well, they might have to use a taiaha, all kids really want to have some ownership of it and not just emulate them.

Nicole Hoey (Pukana)

Each producer articulates a need to engage with global trends and material. However, the degree to which each programme allows imported material to dictate content and themes for a particular show varies. The perceived need to global trends and products continues to illustrate the complexities of balancing broadcasting and funding ideals with what the audience are able to access in other media sites. There is a sense from the comments above that there is inevitability about this kind of material, it has to be dealt with given the environment that these programmes operate in. To gain an audience and therefore be competitive this kind of material must be included.

This discussion also demonstrates the authorship and construction that the programme makers are reluctant to acknowledge. There are a number of different filters mentioned. Janine Morell-Gunn raises the age appropriateness of content, with the ' $\mathrm{M}$ ' rating of the latest Harry Potter movie causing the competitions and interaction with the material to be framed differently, and using 'editorial licence' with music videos. Mary Phillips demonstrates elements of construction by consciously not 'embracing' imported material, indicating that it is not as valuable as using it to create more original content. In the case of Pukana the use of contemporary popular culture and trends is specifically in order to foster an engagement with Māori language and tikanga.

\section{Cultural Identity}

The issue of reflecting cultural identity in children's television is effectively illustrated by Anna Allbury from Studio 2 when articulating how cultural identity works in terms of funding:

I know that in [the] NZOA statement of intent for children it says 'innovative local content providing NZ identity and culture for the $21^{\text {st }}$ century'. It's incredibly broad 
and it's almost like 'what's your spin on that?' so we say 'this is what we'd like to do and this is what we think' and then they sort yay or nay it really.

This acknowledges both that NZOA acts in a role of cultural identity gatekeeper, and the potential difficulty of using an idea like cultural identity as a guiding factor in programming. As indicated above, the broad nature of the term allows for different interpretations and incorporations of the concept. Given that the necessity for providing these representations has been expressed by broadcasters, funders and producers, the different (or similar) ways that they define and interact with the concept will be identified and demonstrated in this section. The key themes that emerge here will be discussed in more detail in the final chapter when they will be juxtaposed with the audience study.

\section{Reluctant Definitions}

Given the role that cultural identity appears to have in funding decisions, there is a need to examine the way that NZOA understand and conceptualise this idea as this indicates the kinds of 'reflections' that can be expected from children's programming. Jane Wrightson (NZOA) explains her reluctance to be tied to a particular definition or understanding of cultural identity:

No, belonging to this place I suppose but again I don't find defining, definitions like that particularly helpful again because of the range of work that we do, if you turn that question on its head, which we have sometimes had to consider, could an Australian programme maker come in here and make a New Zealand programme, answer, possibly there's nothing stopping them, but our first question would be what do you understand of this society and this culture and what makes you think that you can reflect that back to a NZ audience, and if they can answer that question effectively, they may well get funding. But an understanding of our history and our culture and our society and the way it's developing is generally a prerequisite, which tends to be that you need to live here, and have, like most 
programme makers do a reasonably wide range of networks and feelers out into general society.

There is a belief here that New Zealand has a particular culture that requires 'reflection' back to a New Zealand audience, but a disinclination to try to articulate what this particular culture might be. This supports the statement made by Anna Allbury at the beginning of this section where each programme has a particular 'take' on what NZOA require, indicating the difficulty of 'reflecting New Zealand' as a whole. Jane Wrightson's phrase "belonging to this place" also provides an indication of the broad way that cultural identity is understood. This raises questions about how such a broad notion can be 'reflected', leaving room for potential exclusions.

Because of the broad, and somewhat reluctant, definition of cultural identity provided by the funding body that actually presides over what this concept looks like in children's television it is necessary to engage with how the producers understand the concept. As the producers have successfully negotiated the funding process they are demonstrations of how NZOA conceptualise this idea. The producers also exhibit the potential impact that cultural identity can have on daily decision making. While NZOA is involved in the initial commissioning and annual funding rounds, they are not actively involved with producers in terms of daily programming decisions. Janine Morell-Gunn (What Now?) explains this:

What NZOA are about is reaching a variety of cultures... We talked about [in the most recent funding proposal] our audience and our ratings, second highest off peak share and interactivity - 7.5 million web sites... It's us taking initiative and saying to NZOA, this is what we want to do but it's within your mandate of promoting culture and identity. They're there for governance not to steer us on content, it's not really what they're there to do.

There appears to be different levels of understanding of the role of cultural identity. At the more ideological level it is used as a frame and guide for programme style and overall goals 
(for NZOA funding), and the practical level with how these goals are translated into programme content and decisions (by the producers).

Producers were not as comfortable with the term 'cultural identity' and preferred to discuss how they 'reflect New Zealand' or a sense of 'New Zealand identity'. Cultural identity was defined as broad and all-encompassing:

I think it's everybody and everything, you and I are Pākehā but we've had completely different cultures l'm sure.

$$
\text { Mary Phillips (Sticky TV) }
$$

I think everyone's got a different interpretation of it. I think most New Zealanders cultural identity, some portion of it is steeped in the Māori culture and being proud about being a New Zealander and you go to the bars in England and you see people standing up and doing the haka who probably have no idea what the words are.

$$
\text { Nicole Hoey (Pukana) }
$$

Yeah, culture is just everywhere, it's like we went to Dreamworld and we'll make tshirts and the presenters will wear a t shirt and we just get a transfer of a kiwifruit or a cut out of NZ for Serena to wear and a Taiaha for Tamati, wherever we go we are. Everything you are and you do, your identity is everything, it's in every game.

$$
\text { Janine Morell-Gunn (What Now?) }
$$

The discussions above move from broad notions of culture to specific New Zealand iconography very quickly. Nicole Hoey's assumption that the cultural identity of most New Zealanders is "steeped in the Māori culture" and Janine Morell-Gunn's description of using iconography such as kiwifruit as an expression of national pride demonstrate the differences in the way that they categorise aspects of New Zealand identity. These differences demonstrate the difficulty of purely 'reflecting' a concept that has varied understandings depending on the programme creator. 
'New Zealandness'

Even though the 'reflection' is of a younger audience there is still a presence of traditional tropes of New Zealand identity. This is particularly so for What Now? who consider their Christchurch location gives them a "better" position to understand what New Zealand is 'really' like:

Making it in a town like Christchurch you're better able to reflect it's national identity... being in Christchurch we're really into reflecting all of NZ, so whilst a third of the population live in the four main centres, two thirds actually live in small towns. So Spyrider has been fundamental to getting out amongst those small towns...we just get into every little nook and cranky with that satellite of ours and being able to really tell some great stories and reflect the things that kids are into.

Janine Morell-Gunn (What Now?)

The fascination with "small town" New Zealand echoes Claudia Bell's observations discussed in chapter one. "Spyrider" provides What Now? with what they consider to be a legitimate claim that they are not only able to accurately "reflect the things that kids are into", but also to reflect "national identity". This suggests an overriding concept that small town New Zealand is in a better position to reflect 'New Zealand' than the other programmes. Being able to get into a range of different locations does give What Now? access to more of its audience, but there are particular ways that these small towns are framed by the show, as co-producers Reuben Davidson and Emma Gribble explain:

RD: Spyrider's a big thing for What Now? and the way that we make it at Whitebait, we've created a satellite team and a satellite presenter, Tamati who goes out and gets into parts of New Zealand where generally you only see a film crew when they are rolling in for news to do a bad news story, so it's like celebrating all those small towns and finding the quirk and the kids and the quirky adults and the extreme things they do and the simple everyday things they do and bringing them altogether... it kind of endorses it for the other kids so it gives it, it 
celebrates that hokey, kiwi small town thing rather than being a kids show where a couple of good looking presenters sitting in front of a screen and producing cartoon after cartoon or linking other stuff together, that's just copycat, homogenised, regurgitated Americana and it's just unashamedly kiwi and whatever happens in those small towns is what you see on Spyrider on that weekend.

EG: It is quite a natural thing for us now, because a whole half hour of our show which is broken into 10 links is Tamati in a small town. If he's in Ngaruawhaia then we've had our researchers spend weeks researching Ngaruawahia for what is cool about that town so you know we have the waka arrival, we go and visit the Māori Queen, we go and visit Mildred at the shop because she collects teaspoons and she's famous in Ngaruawahia... we have a research team that spends two or three days every week researching a town in New Zealand that we then make a key focus, so that's very kiwiana.

The framing of New Zealand identity as being found in 'quirky small towns' presents the particular frame that What Now? has for representing 'New Zealand'. The ability of programme makers to decide what is "unashamedly kiwi" and considering this representation to be a more authentic expression of New Zealand identity. This presents a challenge to the notion of being able to 'reflect' the previously broadly defined notion of cultural identity. What Now? demonstrates the way that a limited frame of 'New Zealandness' can impact on the way that a particular programme will interact with and understand cultural identity.

\section{Creating 'Confidence'}

Reuben Davidson's argument that Spyrider's visits to small town New Zealand is an opposition to "copycat, homogenised, regurgitated Americana" exemplifies common argument used by the interviewees when discussing the role of cultural identity in their programme. They indicate perceived need to create a point of difference from the imported programming available and to create a sense of cultural confidence for the audience through 
their programme. Janine Morell-Gunn (What Now?) marries her earlier use of traditional "kiwi" iconography with this creation of confidence:

Everything you are and you do, your identity is everything, it's in every game, if we're doing 'Tug of Mud' and we've got the soccer team and the basketball team and the kids and they've been down at their local sports field, I mean that's part of our culture, everything we do and a lot of the games we do we're always using the pavlova and the no.8 fence wire and that sort of thing. We're always using wardrobe and props and things that say 'us', but you're not saying that NZ is better or different to anywhere else, it just is. But what you're trying to show is to be strong and confident about who you are and what you are, celebrate what you are, what we are is good, this is who we are, it's giving kids a sense of confidence.

What is interesting in the discussion above is that there is a difference set out between developing an overt sense of national pride or patriotism and creating a "confidence" in being a New Zealander. The idea here is that "what we are is good" but not better, or even different to anywhere else. This again invokes the idea of 'reflection' by claiming that New Zealand (or at least a particular understanding of it) "just is" and that is what the programme aims to reflect and interact with. Mary Phillips (Sticky TV) echoes this idea of confidence:

[lt is important that] that they see that the way they live, that they way it is, is good, that it's not American, it's not Australian and yet we do of course talk about this is happening here and this is happening there globally, but really we try and make niche here about what kids do, and really try and reflect New Zealand.

The need to keep an eye on what is happening elsewhere and the view of New Zealand children as a "niche" relate to the way that New Zealand are the minority within their own television schedule. This need also indicates the duality involved in being able to 'reflect' cultural identity. Illustrating what children "do" needs to be balanced with an awareness of the outside (global) world. This indicates that there is the potential for their audience to understand their culture through wider global trends and definitions rather than being purely 
receptive to content that is only New Zealand focussed. Whether this is driven by the broadcasting environment or the audience themselves will be explored in more detail in the final chapter with the results of the audience study. What is of particular significance to the current discussion is the juxtaposition of traditional "kiwi" imagery and attitude and a strength of conviction in "reflecting New Zealand" to create a sense of confidence, and the underlying notion of the significance of imported material and trends and the difficulties this can create for the 'reflection' of cultural identity.

\section{Accents}

A source of inspiration for this thesis was Studio 2s character Mick the movie guy (appearing in 2006). Mick is a New Zealand actor playing a caricature of a middle-aged, white, American male who would spend the duration of the programme reviewing major children or family movie (predominantly US created) releases. While this representation marks out some comical differences between New Zealand and American cultures in terms of accent and mannerisms, it also maintains the role of the American as the cultural authority - the presenters seem boring in comparison to their eccentric American counterpart. ${ }^{82}$

Accents provide an example of the difficult position between the importance of 'reflecting' New Zealand and negotiating imported material and influence. Different characters and sketches can often involve the use of different accents, particularly American to illustrate entertainment and cultural authority.

Mary Phillips (Sticky TV) explains her conscious "policing" of accents and the need to set an example for her audience:

I so police that, [using different accents] I really police that. What's important is that whole thing, Drew [a presenter] is someone because he's in that musical world and he was in McDonalds Young Entertainers so he's come from that

82 Shepherd, Ngaire (2007), Seen and Not Heard? Cultural Identity in New Zealand produced children's programming, Conference paper presented at MEDIANZ conference, Wellington: February 2007. 
entertainment side, it was him that I had to really get to just lift his game a bit about the spoken word because otherwise we're just hearing all that garbage, well it's not garbage, but what kids speak and it's good for them to have models that speak properly and speak in a New Zealand way and not use words that perhaps we wouldn't.

This provides a specific area where the ability to "reflect children's worlds", as well as a particular sense of cultural identity becomes more difficult. The conscious choice is made here to not use "what kids speak" but to "speak in a New Zealand way", illustrating a particular editorial decision about using a "New Zealand way" over what the audience prefers to use/hear. A connection between "entertainment" and the dropping of a New Zealand accent is made when she discusses one of her presenters, Drew, who is also a musician and his ability to speak "properly" has been impacted by that industry.

On the other hand, What Now? uses accents in sketches to create humour:

[W]hen it's [accents] called for and you are parodying, yep, and when we do supernanny we did that, but all the other characters in it are us, so it doesn't really worry us... we've got the cheerleaders and they do do a Britney, Whitney etc so that is an American sketch and, we've got What da Baa? Which is the sheep with the singing lips which is kind of the hip hop, so it's relevant to character I think and then everybody else around it is still NZ accents. I don't really have a view on that, and then in the show they're just themselves.

$$
\text { Janine Morell-Gunn (What Now?) }
$$

Accents are used in this context in order to parody particular characters and television shows such as Supernanny and America's Next Top Model. They are viewed as an extension of that parody. When the presenters are 'out of character' they speak in their own accents. This continues an association between entertainment and imported material, which is a regular feature in the media that children are exposed to. However, accents are also used in sketches that are created without a specific programme as an influence, such as the 
cheerleader sketch in What Now? This demonstrates an integration of imported influence and lifestyle into original material on the programme. Again illustrating the tension between reflecting "New Zealand culture" and material that is considered relevant and entertaining for children.

\section{Ethnicity}

While use of accents provides a small snapshot into the complex relationship between cultural identity and 'entertainment', the inclusion of different ethnicities in each programme was commonly mentioned as an expression of cultural identity. Unexpectedly, ethnicity became a revealing discussion about how actively constructed this aspect of cultural identity can be.

While What Now? claimed that their Christchurch location enabled them to more accurately reflect all of New Zealand, this became more complicated when considering ethnicity. Emma Gribble and Reuben Davidson (What Now?) explain how they need to actively represent different cultures in their programming, relegating ethnicity to a required visual representation:

RD: I think one of the things for us, because we're in Christchurch and in the South Island we have to make sure What Now? is for all of NZ and so we're always really conscious of reflecting the whole of NZ in our programming.

EG: We often will be making a promo and we will try and especially find an Asian kid, a Māori kid, or a Pacific Island kid, yeah we will do that... like Reuben said, in Christchurch it is real white bred down here, like we do have ethnicity but it's nothing like Auckland or Wellington, but we definitely are aware of it so we do try and get kids on of all different ethnicities.

When compared with their earlier statements about an "authentic" representation being better achieved in Christchurch, there is conflict in their admission that the city is "real white 
bred" and that they have to "try and especially find" children of different ethnicities to help them provide their reflection of the "whole of New Zealand". The fairly non-chalant description of finding "an Asian kid, a Māori kid, or a Pacific Island kid" alludes to them being used as providing a sense of visual diversity rather than being involved in a reflection of their culture. Relegating ethnic difference to a visual representation indicates an understanding of cultural identity that is based in the views of the dominant culture (Pākehā).

Providing visual diversity was also raised by Emma Watkinson from TV3. Here she explains the need to have a mixture of kids to accurately reflect New Zealand:

I think it's really good to have a mixture of kids so we reflect our growing nation you know, so that we have Māori and Pacific Islander and we have Asian children, so we reflect what NZ is made up of now, and that's really important, we like to have a mixture of girls and boys, so in that respect yeah, but that sort of thing comes pretty naturally I think, I mean obviously we want it to be there but it's easy to reflect that we have so many kids apply to be on our shows and everything like that but I know that there's just you know and conscious decision to make sure we get them in there and that they're seen.

As with the statements made by Emma Gribble and Reuben Davidson of What Now? there is a clear desire here to visually show different ethnicities. Further cultural reflection, however, seems to stop there. This reinforces the discussion noted earlier where children are viewed as children before being understood as belonging to a particular ethnic group and therefore programme makers appeal to their audience as a homogenous group of children, rather than children from a diverse range of ethnic backgrounds. Emma Watkinson also demonstrates a further key understanding of reflecting culture, that cultural identity (and therefore ethnicity) is inherently 'natural' and will inevitably be reflected through a programmes creative process. 
'Natural Reflection'

While the selection process involved in providing a range of ethnicities was discussed above, the passage below from an interview with Anna Allbury and Pallas McTaggart from Studio 2 examines the role that actively selecting material plays in other areas of programming:

PM: Hmmm, interesting question, well there is and there isn't, because we don't purposely go out to a specific school with that specific reason in mind... we're not targeting to anything particular... I don't think we go out there with anything in mind it just happens naturally...

AA: I think with us that we've got to try and cover as much as we can...a cultural presence as well, almost by accident, which is fantastic, I mean our presenters, we've got a Samoan presenter, a European presenter, a Chinese presenter and a Māori presenter and it's not because we went out and searched for them, that's just how it happened, and I think that sort of reflects our content as well.

PM: Yeah l'd agree, it just sort of happens naturally...that being said we don't always pick the person with the best brief, otherwise we might end up in Wellington four times in a row and we have to actually look at it and say 'well, where haven't we been, is it a sport we haven't covered and do they have a good brief when they're sending it in so you do have look at everything not just one thing.

Would ethnicity factor into those decisions?

Pallas: Not for that no, no absolutely not no, but five times out of ten they'll be Polynesian or Māori or yeah or South African... it just happens naturally once again. 
This discussion demonstrates the conflict between selecting content and participants for the show and the ability to 'reflect' the audience. The way that 'natural' is used here appears to be a way of avoiding the suggestion that these aspects of the show involve an engagement with selection and construction. Designing content and competitions inevitably involves selection and editing of what (the producers think) the audience may want to see, or of who will appear on the show. The "natural" reflection of the audience is disrupted by the need to not end up "in Wellington four times in a row". This is also evident in the way that Studio 2 views cultural identity:

We want to make the content we make for them and that they make for us available where they [the audience] are, and for us that is cultural identity really, creating something together.

\section{Anna Allbury (Studio 2)}

Creating something together provides a different perspective on cultural identity. This definition ultimately describes cultural identity as appealing to children as a community and fostering an interactive relationship with content. While seemingly forward thinking in the way that there is not the same reliance on traditional ideas of New Zealand identity seen in What Now? and Sticky TV, the discussion regarding selection demonstrates that content decisions are still ultimately the producers decision. This makes the ability to "create something together" problematic when the relationship is not equal.

What is evident in the discussion of selection is Studio 2s preference to speak in terms of diversity of talent rather than actively seeking a visual diversity as seen in earlier comments by What Now? Focussing on talent means that factors such as ethnicity will happen "naturally". However ethnicity is still an issue when considering cultural identity. This is seen in the ethnicities of the presenters being an example of a "cultural presence" and one that occurred "naturally". The discomfort with the suggestion that ethnicity is an active consideration in programme content further illustrates the sense of attachment that programme makers feel to the ideal of 'reflection', regardless of how conflicted their accounts of the 'reflection process' are. 


\section{Utilising Māori Culture and Content}

A further issue of cultural reflection is Māori culture and content. Jane Wrightson explains the role of this content when asked what aspects of New Zealand culture stand out in the funding process:

[W]e will almost certainly look for the inclusion of Māori material as and when appropriate, and indeed other New Zealand ethnic material as and when appropriate, in other words it's easy enough to do PākehāNZ perspectives and part of our role is pushing the programme makers and broadcasters a little, going 'have you thought of other perspectives as well?' given the changing nature of our country.

Reflecting Māori culture and content is seen as separate from other forms of ethnicity, however it is also considered inherently natural, as Emma Watkinson (TV3) explains:

I think you'd see it pretty much reflected, I think that most people would want to make sure that we were reflecting NZ culture in that respect. Obviously we like to get Māori culture in there particularly so that we get Drew on Sticky TV as a Māori speaker, and that's part of his sort of everyday stuff, him speaking Māori in the show as a sort of natural by-product, I mean we make sure it's there but it's there in such a way that it's natural.

While Jane Wrightson encourages a range of perspectives to enable a "reflection", Emma Watkinson illustrates a conflict between Drew speaking Māori being a "natural by-product" of him being Māori but "we make sure it's there". This element of construction is also evident in Mary Phillips (Sticky TV discussion of aspects of New Zealand culture that are important to her programme: 
[l]f there is such a thing as bicultural, there probably isn't yet in New Zealand but one day there may be... that presenter that l've just found now he's truly bicultural, he's walked in both worlds and he was dux of a really Pākehā school because he won a scholarship there and he walks in both worlds really confidently and that to me is truly bicultural, so I think that we can only just do our best to show it like it is, I don't think we go out to say 'well we've got to push brown faces' or whatever.

The indication that a value of this presenter lies in his ability to represent a particular view of biculturalism indicates a calculated decision regarding this kind of representation. There appears to be a fine line between actively seeking a "brown face", which all producers claimed not to do, and finding presenters who are able to 'reflect' different cultures being an attractive quality. Biculturalism is also understood here as Māori being able to "walk in both worlds really confidently", and become "dux of a really Pākehā school". This indicates that the responsibility of biculturalism lies with Māori being able to effectively negotiate a Pākehā world, rather than the other way around. This understanding of biculturalism demonstrates that a programmes ability to "show it like it is" is inherently tied to larger discourses that impact on the way that content is framed. Māori content and culture is supposed to occupy the difficult position of being actively sought, but somehow be inherently 'natural'.

An alternative view of the role of Māori culture in cultural identity is provided by Nicole Hoey of Pukana, who has stronger views about the relationship between Māori and a New Zealand identity:

I think that the cultural identity of the show is taking the language to the street, that has to be our cultural identity...To me cultural identity in terms of being a New Zealander... the only unique cultural identity that NZ has got is the Māori culture.

Nicole Hoey was the only programme maker to articulate her programmes particular cultural identity as being central to the overall focus of their programming. She did not utilise any traditional [and predominantly Pākehā] tropes of New Zealand identity or notions of 'reflecting New Zealand'. Her view that Māori culture is the only 'unique' cultural identity that 
New Zealand has acts to further emphasise the essentially Pākehā-centric frame that is used by the other programme makers and their reluctance to engage with issues of content selection. Pukana adds a perspective to the discussion of cultural identity that is not seen in the discussions of the other programmes. Pukana has an active engagement with a specific definition of cultural identity and an understanding of the importance of this definition.

\section{Conclusion}

For these programme creators, the concept of cultural identity seems to be both broad and vague, and a highly simplified and easily recognisable concept. There is a level of discomfort from programmer makers at being in a power position with children and having the responsibility of providing the audience with their sense of local orientation. This is apparently resolved by their reliance on notions of 'reflection' even though such a concept is very problematic. Indeed, elements of construction were obvious in the discussions of the way that they conceptualise and interact with their audience and in the ways that the difficult funding process and the demands of the broadcasting environment are negotiated. The programme makers, however, feel that their creative process is interactive and audiencecentred. This connection to their audience is used to support their claims of 'reflection'. There is also a strong connection to ethnicity and providing what they believe to a 'natural' representation of the different cultures within New Zealand. These 'natural' representations are also considered to not be affected by the 'inevitable' engagement with global products and the use of foreign (mainly American) accents. While there is a reluctance to define and articulate what 'cultural identity' means, and a strong acknowledgement that it is an idea open to interpretation, the understanding of cultural identity is mainly expressed in terms of traditional iconography and connections to a nostalgic Pākehā version of New Zealand.

The significance of these articulations will be contemplated in more detail in the final chapter where they will be compared and contrasted with the findings of the audience study to examine the way that cultural identity is understood and utilised for New Zealand produced children's programmes. 


\section{Chapter Four - Audience Interviews}

Local content is the "other" in New Zealand children's television schedules. This has resulted in a strong demand from children that locally produced programmes be accessible, interactive and provide a sense of connection and community. This chapter is based on focus group research and examines how New Zealand children's programming is interpreted and engaged with by the intended audience. It focuses especially on what makes the programmes appear New Zealand produced, and how this affects the way that this audience identifies with them and their expectations of local programming.

The participants held strong opinions, and were rarely inconsistent about the programmes they liked or disliked. Another striking aspect of the data was the similarity of opinion across the groups. There were clear favourites amongst the entire sample and usually similar reasons for liking or disliking a particular programme. The children interviewed also exhibited a clear set of expectations of, and attachments to 'their' programming.

To begin to deconstruct and open out this material, it is necessary to discuss what is liked/disliked or "boring"/"cool". The first step in this deconstruction is to briefly examine the key ideas and reactions to each programme individually before a general discussion of larger themes and opinions.

\section{What Now?}

What Now? was the clear favourite among the interviewees. It regularly dominated conversation and would be used as an unprompted point of comparison. What Now? appeared embedded in the weekend routine and it would often be watched in bed on a Sunday morning. The conversations tended to get more animated when it was being discussed, and there appeared to be a level of comfort with and ownership of the programme. The children would often discuss the history of the programme, authoritatively listing previous presenters and segments that they preferred, demonstrating their close connection the programme. 
Jada: I like it when Caro and stuff was on it, that was cool and they changed to all the young presenters and stuff and it spoilt the fun

Dora: Like props boy and that

Reka: Yeah props boy was cool

James: Yeah that guy with that hat and that

Aroha: That's props boy

(Group 3)

This preference for older presenters and skits illustrates the only real criticism of What Now? and demonstrates the place that the programme has in their cultural memory and experience. They are able to speak with more authority about the show because of its longer history and place in their television routine.

What Now? is seen as the benchmark and originator for the other programmes, which either extend on ideas seen in What Now? or were labelled as trying (unsuccessfully) to "copy" them. The three key aspects of What Now? that the children wanted to incorporate into the other programmes were the length, the 'Spyrider' feature, and the inclusion of and interactivity with other children. 'Spyrider' and its presenter Tamati were mentioned throughout the interviews. 'Spyrider' is a segment of the show where Tamati travels to a different New Zealand town each morning, and the children from town and surrounding areas come to be part of the show.

What would you add to What Now?

All: Nothing.

Is there anything you don't really like about What Now?

All: No!

Talia: Tamati, he goes round the schools, he travels everywhere

Arapera: He's been to Palmerston North before

Bea: He went to Linton and I went there 


\section{Arapera: Yeah same}

Talia: Yeah, cos they do go round schools, Tamati does and that's cool

Waireka: Yeah there's nothing wrong with it.

(Group 4)

This excerpt is indicative of how, when asked what could be changed about What Now? none of the interviewees had any suggestions beyond switching presenters back to older presenters that they "liked better". This further demonstrates What Now?'s role as the benchmark of quality and ideal local experience for these children. This role was enhanced by their experience of the programme visiting their area.

\section{Sticky TV}

Sticky $T V$ is also considered a favourite. It was often compared to What Now? and holds a similar appeal because of its diverse range of segments and inclusion of children within the programme. Group 4 demonstrates this:

So what do you like about it [Sticky TV]?

Talia: Animation

Bea: It's entertaining and they always, yeah

Talia: And it's children, they talk about children

Bea: And they have facts and brain teasers and then they always answer stuff

Talia: And then they change up to teenagers

Arapera: And they give away free stuff

Waireka: You can just put your name in

Te Pura: They do makeovers, that's cool!

Talia: They show all this fun stuff and who's going to win

(Group 4)

There is an affection for the presenters and a connection to and enjoyment of the humour used in the programme. A strong feature is the segmented format, where the different stories 
(for example, a makeover) will be stretched out over a week with new instalments each day. Three different segments feature in each episode. The more interactive elements such as the blog and the chance to enter competitions were often discussed, as were the more basic interactions of brain teasers and different daily facts. The interviewees largely felt a sense of connection to the programme because of its clear focus on children. As Talia says, "it's children, they talk about children". Sticky TV encourages this connection through the interaction between the presenters and different children in the segments, the inclusion of requests and suggestions from viewers.

\section{Studio 2}

Studio 2 was the least favourite programme and the most discussed. It seemed easier for the children to articulate why they dislike something rather than why they like something. Subsequently, Studio 2 is often involved in comparisons and deductions about what they do like and therefore the programme has a very strong presence in the data collected. The children generally described the programme as "boring". When asked to explain why it was boring the main response is that there is "too much talking". The key criticisms stemmed from this idea. There is not as strong a connection with the programme, because there is not the same level of interaction with children as in the other programmes:

Bea: Sometimes they think it's cool, like they do cool stuff but it's not really that cool, they just try

Arapera: I think they should have cartoons in it, it's kind of boring just watching them all day

Te Pura: Yeah, they just talk, I always just change the channel

Talia: And why can't they move around?

(Group 4)

The absence of movement and emphasis on presenter-to-presenter or presenter-to-guest interaction rather than interactions with children are at the heart of Studio 2 being labelled "boring". This leads to a lack of connection for the children compared with What Now? and 
Sticky TV. The style and approach, described as "fake" and "trying too hard", are regarded as not as funny as the other programmes. The use of computers and live interaction with the website The-Hub was used as an example of the programme being "boring" and not having some form of activity that the children felt they could replicate or be involved in.

\section{Pukana}

Pukana was a difficult programme for many of the groups, because they did not feel as though it was intended for them. It was quite clearly labelled a "Māori programme" and the importance and relevance of this was debated. There was a level of discomfort here because the majority of interviewees felt unable to speak about the programme with the same degree of authority as the other programmes. This resulted in suggestions of translations and sections in English to help them feel part of the programme. Those children who had the ability to follow and understand the programme also suggested that there was the potential for people to feel left out and that this was not a positive attribute for a children's programme. This discussion by a group from the bilingual class illustrated these two opinions:

Aroha: I think it's [Pukana] good that they have Māori ones, because people that like don't know that much English, it's really good for them, because they don't have to just watch English stuff all the time

Reka: And most of the shows don't have Māori on it James: But sometimes it has too much Māori so you don't really understand what they're saying

Aroha: But it's made for people that understand Māori, so that's cool James: Yeah, cos it's on Māori television

(Group 3)

Here, Reka (Māori) demonstrates that she can see the value in the programme as it is useful for people that speak Māori. James (Pākehā), however, considers that there is also the potential to feel that it does not apply to everyone, inhibiting a wider connection such as that felt with the other programmes. 
Pukana was described by one participant as "a copy of What Now? but in Māori". Indeed, both programmes involve seeing a lot of children and visiting them at their schools and in different locations. Comparisons can also be drawn through the use of parody: both programmes use adult formats and adapt them to their audience. Pukana does this with music videos by re-creating them in te reo. There is a strong sense in the discussions, however, that some children separate the two programmes into one for Māori and one for "us". Even those children who identified as Māori felt a stronger connection to What Now? than Pukana, indicating language as a barrier to creating a wider sense of connection.

In further discussions, two key themes become clear. Firstly, there is an expectation that the audience will be able to participate in and feel connected to a 'kids' community. Secondly, these children understand and conceptualise 'New Zealandness' in a way that has a significant connection to a traditional discourse of New Zealand (and particularly Pākehā) identity.

\section{A Sense of Community}

A noticeable feature of these interviews is that the interviewees were very comfortable with the label 'children' and 'children's or kid's programmes'. They often asserted their difference from adults and teenagers and had a clear recognition that they are a different audience with different demands and expectations that need to be met. One expectation that became strikingly clear is the need to create a sense of community through the programmes. The programmes are seen as an opportunity to see and learn about other children in similar situations.

This was evident in the constant criticisms of Studio 2, where there was not same ability to bond with the experiences of other children as there is with the other programmes.

Te Pura: I kind of like the presenters [on Studio 2], but I don't like how they talk all the time 
Bea: They talk and talk and they don't show any like programmes or anything, they just talk all day

Talia: Like Sticky TV they should have like couches and that and be outside

Arapera: And do quizzes

Talia: They should go to schools

Waireka: There's not much kids

Te Pura: Nothing includes kids and that they just talk.

(Group 4)

The constant reference to how much the presenters "talk" indicates that when there is a lower presence of children within the programme there is a disconnection between presenters and the audience. Watching adults "talk[ing] all the time" does not offer these children an experience that is any different from adult programme or which fosters a unique connection with them as an audience.

The mention of quizzes and schools reinforces the kinds of expectations placed on the programming by programme makers. One expectation is that children's' programming, while being entertaining, will also include some form of learning and educational qualities. This was welcomed by the participants. Showing children, schools and including elements of daily life appears to create a unique connection for the audience, making it clear that they are the desired target for the programming.

\section{'Kids' Only' Space}

A further way that this desire for a community is exhibited is through the concept of a 'kid's only' space. This is demonstrated in a clear sense of ownership of and authority over the different programmes. An example of this is seen when discussing how Studio 2 could be improved:

Mark: But Studio 2's boring

Quinn: Studio 2 was made by adults, what do adults know about what kids want? 
Mark, Chris, Nicole, Hilary: Yeah!

Quinn: What do they know about what kids want?

Petra: Because they were kids, so they should be able to know what kids want

Quinn: They probably didn't even have TV when they were kids. They should actually grab some kids and ask them what they want

Paris: At least they talk about kids more than adults

Quinn: Yeah but they should grab kids and say 'ok, we're gunna change Studio 2, none of you seem to watch it anymore, what can we do to make it better?'

(Group 1)

Here these children explicitly differentiate their space from adults and their belief that adults are unable to really understand that space. The same idea was often more subtly articulated through the comments about of the absence of children 'doing' anything and seeing too many adults "just talking". Several children commented that they were much more interested in seeing other children 'doing' something rather than being shown something by an adult. Again, this confirms an attraction to a creating a children's community.

The participants' desire to see more children on screen as well as to mark out their own television territory is also seen through a clear preference for longer, linking programmes such as Sticky TV and What Now? Longer programmes that contain the traditional imported cartoon content within them allow the audience to further refine the definition of 'their' space. Having the two different styles of programming (imported animation and local variety) interact with each other works to make the space both more appealing and connected. This preference became evident during discussions about why these children liked Sticky TV as well as how they would improve Studio 2:

Reka: I think it [Sticky TV] goes for a really good amount of time, it's not too long Jada: It's a medium length

Aroha: And it's cool how they don't have the cartoons and go straight onto ads... Dora: Yeah

Tane: They cut it and then you get a second part of the cartoon 
(Group 3)

\section{[On Studio 2]}

Chris: Expand the time to about an hour and take snippets from other shows

Petra: But how are they going to put more shows in?

Mark: They have 30 minutes, that's why they can't put heaps of shows in, they only have 30 minutes

Quinn: Well only one then.

Mark: They've still got to speak and do all that

Quinn: It should go for an hour and then they could fit other stuff in

Mark: Maybe it should go for an hour and a half and then half an hour of that could be other shows

Petra: You get ones for like 15 minutes

Nicole: If they cut out the ads that could make it shorter

Mark: Yeah, on Sticky TV it's better because there's like Part 1 of the programme, then they speak and then it's part 2 of the programme

Petra: Yeah like What Now? is longer they have like an hour

Chris: They have 3 hours.

Studio 2 is the shortest of the programmes under discussion and there was a desire to extend it and include other programmes and segments in order to break up all the "talking" and make it feel more like their preferred programmes. There has been a history of this longer 'linking' style of programming in New Zealand, and this has generally been regarded as having more imported content than locally produced. ${ }^{83}$ These children like interaction between the presenters and the cartoons, incorporating them into the programme and allowing the local segments to set the tone of the programme rather than the cartoons. This lends itself to the argument that this is more an exercise in maximising their ability to claim a sense of ownership over the programme rather than about specific international animation brands.

83 Lavranos, Eileen (2003). "Children's Television Programming in New Zealand: Like the Kiwi an endangered species?" paper presented at ANZCA03 conference, Brisbane, July 2003, p.3. 
The reaction to Tamati's departure from the 'Spyrider' segment of What Now? also demonstrates the kind of protection and ownership that the audience feels for the programming and presenters. Tamati was frequently mentioned in discussions of the positive features of What Now? and the different changes that the children would make to the programmes. There was a lot of comment about his leaving and why he would leave. One interviewee complained:

Cora: Because they've put Tamati off What Now? and put him on Breakfast and it's like, what kids are watching breakfast? That's for adults.

(Group 2)

Cora's observation that Breakfast is not for kids emphasises the importance of the programme being a 'kids' only' space, and that Tamati is breaking that space by leaving for an "adults" programme. The discussions about Tamati also illustrate that this created community goes beyond being a purely virtual or televisual community. Rather, the community is expected to be accessible in a very tangible way. This audience enjoys feeling both that they are a part of the process of the programme through interactivity and also that they are considered an important part of the audience regardless of their proximity to the actual studios. Tamati represented a direct connection to the programme. He travelled New Zealand stopping in different towns (including Linton, just outside Palmerston North) and interacting with the local children.

James: I don't like how it's [Sticky TV] only in one place and they only get people from that town and that

Aroha: I mean you can send in mail and that but it would be cool if we could get people from here because we don't really have one in Palmerston North because it's not that big

Reka: It would be cool if they had like different places each week James: Like that's how the Spyrider on What Now? works is it goes to different towns 
Aroha: And I like on What Now? how they have one person, like they have Tamati

how he moves around the area, so everyone kind of gets a turn, he went to Linton, that was pretty funny.

This discussion highlights that fact that being able to get involved with or be on a programme was the most desirable quality in children's programming. This also adds to the earlier observation that the children are interested in seeing other children in their programming so they can feel as though they could be in their position. The community created by 'Spyrider' is further reinforced because everyone feels as though they "get a turn" and have equal opportunity to be involved as well as watch children in similar situations and smaller localities participate.

Humour

This 'kid's only' community is further strengthened by the use of humour in the programmes. Humour has the ability to create a community through shared jokes and experiences and the humour that creates the strongest reaction from the children is when adults are made fun of or parodied. It was difficult to get specific explanations about what made something funny, but it became evident in their discussions of the different things they liked about the programmes.

Mark: Yeah I know, I've watched them film it with Tamati, they've got like lots of fans and people in the studio

Petra: Yeah they should do it like What Now? and have heaps of kids

Mark: Yeah they need the funny stuff

Petra: Not just like funny stuff for like adults

Mark: When I was out at Linton with Tamati he was like, he was, he made the show really, because he made it really fun and he was like today on the show... something else and this and that... and it's that bogey up your nose' 
Nicole: He jokes a lot.

(Group 1)

Aside from the slapstick and scatological humour usually associated with children's programming, there was a particular interest in the parodies of adult primetime formats on What Now? and Pukana. What Now? regularly has new parodies of programmes such as 'McClaud's Daughters' based on Australian produced drama McLeod's Daughters and Pukana has a regular set of characters who parody another Australian produced show Kath and Kim.

Arapera: And it's cool they [What Now?] make up their own programmes Bea: And they have different characters

Arapera: And they change that stuff from TV and they change it like New Zild's next top model and then on McLeod's daughters they called it McClauds daughters.

(Group 4)

Parody in this context further strengthens the "kids' only" space by taking formats that are known to be "adult" programmes and recreating them to appeal to this audience's sense of humour. It subverts the power relationship that children experience in everyday life and emphasises the programme as a space that is designed to be for kids where they are able to "make fun" of adults and adult programming.

\section{Technology}

The high focus on technology also contributes to the sense of connection and interactivity in these programmes. As well as enjoying being able to see interaction between children and presenters, these children also demonstrate a desire for the programme to feel accessible to them and interactive. What is interesting to observe about their relationship with technology is that while they are happy to use different technologies to contact and interact with the programme, they are not as receptive to the programme making a feature of new technologies and communication. Criticism of Studio 2 stemmed from its strong focus on 
internet-based activities such as having emails and chats live on the programme as well as having viewers post different photos and information on forums that they have set up. This illustrates a dynamic where these children prefer a visual connection with other children rather than having this mediated through a series of different technologies. As Group 3 explain:

Jada: I would like to change how they [Studio 2] always go by the computer, Reka: Yeah, like every time they introduce themselves and then they'll go to the computers and see what's up on the hub

Tane: Sometimes that's really annoying

Dora: You can't really read it anyway

Jada: Yeah they do it too much.

(Group 3)

This demonstrates a need for the community to be accessible through a visible connection to other children. Introducing another medium between the audience and presenter appears to diminish the connection that the technology is designed to improve. Studio 2 has the most advanced usage of technologies, however it was considered to be the programme that was the most difficult to get in contact with. It was also the hardest show to get on because of the amount of time spent based inside the studio. Interactivity, particularly online, clearly has a role in creating a connection between the audience members where the content can be seen through an interaction with people rather than with a computer, as the following discussion demonstrates:

Caine: It's a bit boring on Studio 2 because they have adults and kids like to see kids shows so they want to have some kids on it Jon: And seeing that kids can actually do it so we know we can do it Brenda: It seems like you have to be famous to go on that show Caine: 'Cos you can send in a letter to go on 'U R Hot' and you could get chosen just to go on TV and get blinged up and all that 
Jon: Like on What Now? you can do shout outs like they'll actually say happy birthday

Caine: Or if somebody wins a goodie bag they say do you want to say hello to anybody

Brenda: And you can go online and it comes up on the bottom.

(Group 2)

The preference yet again to see other children 'doing' something extends to the different forms of interactivity where the audience would rather see children interacting with other children through those mediums instead of solely interacting with the presenters. The presenters who use communication technologies to give "shout outs" and say "happy birthday" create a personal connection that is not present in the viewing of an email.

A more traditional way to involve the viewer is through competitions. This is still an important part of the programme experience. Most interviewees regularly enter competitions, and programmes were criticised for not showing their contact information for long enough. Competitions provide a major point of difference between New Zealand programming and imported material. Being able to enter a competition is a clear signifier that the programme is made in New Zealand and that it is part of their particular community of programming. This is apparent in the discussion below about New Zealand made shows:

Aroha: It's cool because people in NZ get a chance to be on TV

James: Yeah and join in and enter competitions

Jada: Yeah and like American programmes you can't just phone up America

Reka: It's pretty good for our education

Aroha, Jada: Yeah

Aroha: It's good to have NZ stuff, like in What Now? it's really good even the callers and stuff you get prizes from there, better than Studio 2.

(Group 3) 
These children have an awareness that New Zealand programmes have a different value than those made in America. The interactivity and community that has been continually expressed as being a positive and desirable quality is not able to be achieved through American programming. Here the community that is being created and fostered is clearly a New Zealand community. This raises questions about how 'New Zealand' the created community should be and the different signifiers and representations of 'New Zealandness' that they (either consciously or not) gravitate towards.

\section{Cultural Identity}

Cultural identity for children appears to be a sense of belonging to a larger community of children, as seen in the earlier discussions of community creation and accessibility. There was also an understanding that this community was for New Zealand children, and that their programme offered a unique experience compared to imported content.

To examine the way that the children conceptualise this New Zealand community in their programming it is necessary to consider the way that they can consciously articulate 'New Zealandness'. Focus groups were asked to explain how they could tell a programme is made in New Zealand, name some of these programmes and whether or not they had opinions on NZ programmes as 'good' or 'bad'. The purpose of this was to gauge whether or not they had pre-determined ideas about New Zealand television and what a New Zealand programme should look like.

For these children, the consistent marker of a programme being made in New Zealand was that the presenters speak with a New Zealand accent. This was equally expressed as "having an accent" or "not having an accent". The confusion here over which accent is actually an "accent" and which is "normal" demonstrates that the high levels of imported programming available to children does have an impact on the way that they understand 'New Zealandness'. A second observation was recognisable New Zealand geography. The children are able to tell a programme is made in New Zealand because they can see that the presenters are in New Zealand. Occasionally this is through landmarks, but usually it is 
because when they enter the competitions they are able to ring into the shows and entries are sent to Auckland or Christchurch, indicating their filming location.

It was in the discussion of 'New Zealandness' that differences between the mainstream children and bilingually taught children became evident. For the bilingual children, the strongest signifier of a programme being made in NZ was through the use of Māori language and people representing themselves as Māori .

What are some of the ways you can tell a programme is from NZ?

Waireka: by their language, and they go kia ora

Talia: And they represent themself, like 'I'm a Māori ', Tamati was a full Māori Jessica: Because there's Māori

Waireka: Because sometimes they say they're in Auckland or something

Bea: WN has been to Australia

Arapera: Disney's in Australia

Te Pura: On Spyrider they show the map of NZ

Waireka: Sometimes it's just easy

Talia: Tamati was fluent in Māori , well not fluent, but he spoke Māori.

(Group 4)

There is little engagement with any visual aspects of culture (actions, appearance) that a presenter may be Māori, it is only the language that is mentioned. The use of Māori language as a signifier becomes more complex when juxtaposed with the reactions that the participants had to Pukana, which will be discussed in more detail later in this chapter.

There was not a considerable amount of conscious articulation of 'New Zealandness' that moved beyond these concepts, particularly from the mainstream children. However, they were able to offer some reasons as to why New Zealand content is better or worse than imported material. As discussed above, the connection to a community is at the core of what the children want out of their programming, and this was also evident in their discussion of what is 'good' about NZ produced programming. 
Aroha: Yeah, like the American stuff you can't just go 'hello, can I enter this competition' Jada: And they're cool

Aroha: And the presenters don't speak like, accented and you can understand them really easily and that's really good... but sometimes people are hard to understand, like super-nanny, her accent, and you can't get the chance to be in it so maybe there should be something like that for NZ.

(Group 3)

Cora: I like them because you can understand them properly and you get the jokes Brenda: They're fun.

(Group 2)

Nicole: Some programmes that aren't made in NZ seem like they don't really fit here.

Mark: Yeah.

(Group 1)

The comment made by Cora about being able to "get the jokes" demonstrates how a feeling of inclusion can only be achieved through New Zealand produced programming. While they appreciate this connection and 'fit' being made in what they consider 'their' programming, they do not have the same expectation on their primetime choices. As the discussion about identifying New Zealand aspects in programming was kept quite broad and general they also discussed their preferred (generally American) primetime programming and why this is better in comparison to New Zealand made. They expressed a general disdain for New Zealand made programming that has a direct imported comparison such as the Idol, Are you smarter than a $5^{\text {th }}$ Grader? and Deal or No Deal franchises. There was also an agreement among the children that generally American programmes were an important part of television and are a connection to the rest of the world. This section of discussion illustrates this mixture of connections when asked about seeing programmes from other countries: 
Jon: Yeah I think you should, you get to learn about some other stuff

Caine: You want to have some NZ programmes as well because that's what your culture is but everything's American

Jon: But on Mythbusters they had a myth, it was a NZ one, it was a farmer and I think it was involving around methane gas and something blew up, but the one that I thought was funny was the methane one where he went to the toilet and they thought it was the methane and he had a cigarette and he blew up, but that was only because he worked at a methane factory.

Cora: It's sort of important to have other countries and to share other countries values because we can't just care about our country and just say 'thanks George Bush' and...

Jon: And 'woop de doo nevermind'

Caine: Yeah but you've got to have some variety on TV and that, different people Jenna: Like people are just saying 'oh so what' when people over there are actually in peril

Jon: Yeah and the people that actually have a good soul listen to them.

(Group 2)

The importance placed on knowing about other nations and the importance of understanding other cultures can stem from the traditional trope of New Zealand as a small and isolated nation. The discussion above demonstrates the perceived higher value of imported programming. This is a value that is predominantly experienced in smaller television markets that have access to cheaper high quality imported content that raises expectations the production qualities of locally produced programming. This signals a presence of the earlier discussions of New Zealand identity is involved in these children's understanding and expressions of 'New Zealandness'. The discourses used in the discussions of the presenters as well as the discussions of Pukana illustrate an affinity for the Pākehā-centric elements of 'New Zealand identity' that have been framed in earlier chapters. 
As Turner argued, Pākehā feel a need for inclusion. The clear desire to be part of a community and have a distinctive and accessible place where the children feel they belong has been present throughout this audience study. There is also the presence of a specifically Pākehā-centric conceptualisation of identity. A sense of entitlement, importance and of a tension between those that challenge this sense of place became clear during discussions of Pukana with the groups from the mainstream classes.

Jon: Pukana?

Caine: It's that Māori one

Jon: I've never watched that

Jenna: It's a bit like a copy of WN except it's in Māori [said Moo-ry]

Caine: It's Māori not moo-ry

Jon: another thing that annoys me, shouldn't Māori stuff be on Māori TV?

Caine: It is

Jon: Sometimes it's on 2 or 3.

What kind of programme does it [Pukana] look like?

Jon: Dumb, Stupid, boring

Caine: No

Brenda: Māori

Caine: I think it's not

Jon: I think it's stupid what they're doing

Caine: No because Māori people want to learn and that

Jon: Yeah but they should have a translation.

(Group 2)

While there is a clear negative discourse being used by Jon, the way that he is challenged by the other group members also sets up a particular relationship between 'Māori ' television and "our" television. This is the first indication from the children that for something to be included in their community it needs to adhere to certain criteria. There is also an indication, 
from members of Group 2 particularly, that there are discourses already attached to something being considered 'Māori'.

Caine: But we have Sticky TV, What Now? and thing, they only got one television station so they need their part in TV so yeah.

Jenna: What I don't actually like about that is the way it started, like they had that big car that looks like so modern but usually like Māori people are not interested in TVs, they're like bush people sort of.

Cora: No they're not

Jon: How come they're always saying this is our land

Brenda: What?

Jon: Like they've got their own beaches and we're not allowed on them

Cora: No, I don't think so

Jon: You don't watch the news enough then.

(Group 2)

The various comments made here illustrate the connection that children have with much wider social discourses and how this can impact on the way they choose to identify with their programming. Jon illustrates a sense of disconnection and alienation from the programme, and did not understand why he was being made to watch something that did not apply to him as the other programmes did. This feeling of disconnection from the programme also arguably fuels his use of negative discourses regarding Māori, such as a particular version of the foreshore and seabed debate. His feeling disconnection has potentially caused the negative emotive reaction.

These children consider that Māori language impacts on their understanding of, and therefore their connection to a particular programme. The disconnection created by the language raises larger social issues regarding Māori and Pākehā, and because Jon feels excluded from the programme he arguably feels more comfortable expressing his views. This view of Māori content is markedly different to the way that Māori presenters and limited phrasing such as "kia ora" were signifiers of 'New Zealandness'. It seems that Māori content 
is considered to have a particular place in cultural identity, but there are clear boundaries as to when it may begin to encroach on a sense of belonging for Pākehā. The comment from Caine, prior to the negative comments of Jon and Jenna, also shows that while he rejects the more negative comments from Jon, he still distinguishes between programming that 'belongs' to him (Caine) and that which does not "fit". This idea was also echoed by Group 1:

Petra: It's [Pukana] boring and I can't understand most of it

Nicole: It should have subtitles

Quinn: Why? Nobody uses it [te reo] anymore, it should be in French so it's useful or something

Mark: So then you can understand it, it's Aotearoa, why do you need French stuff in Aotearoa?

Paris, Hilary: Yeah

Mark: What about people that want to learn?

Quinn: New Zealanders don't use it anymore.

(Group 1)

Quinn's comments draw on a larger discourse about the 'usefulness' of the language. He also argues that there is a particular way that 'New Zealander' is defined and recognised, and that 'New Zealanders', indicating Pākehā, "don't use" te reo. Mark, Paris and Hilary, on the other hand consider te reo to have a value for people that want to learn it, and claim it as being an integral part of "Aotearoa". They do not, however, signal themselves as being part of this audience that may want to learn. This echoes the discussion of Māori broadcasting from chapter one where that acknowledges the need to frame Māori content for a mainstream audience. Māori Television particularly promotes a need to revitalise language not only for Māori communities, but to increase a level of understanding and awareness from the wider New Zealand audience.

The groups from the bilingual classes largely agreed that Pukana was an important programme to have but was still inaccessible to many and this would be something that they 
would change about the programme. However they were able to make a clearer distinction between being Māori and being able to speak te reo:

Aroha: I think it's good that they have Māori ones, because people that like don't know that much English, it's really good for them, because they don't have to just watch English stuff all the time

Reka: And most of the shows don't have Māori on it

James: But sometimes it has too much Māori so you don't really understand what they're saying

Aroha: But it's made for people that understand Māori, so that's cool.

\section{What would you change about Pukana?}

Aroha: People that can't speak Māori don't get the chance to be on it

Reka: Maybe put more like subtitles in it

Aroha: Yeah write what they're saying down the bottom, it's not really made for people that don't really speak it or anything

James: It would be nice to watch it and know what they're saying and that.

(Group 3)

This distinction between Māori and non-Māori only took place on the level of language with no acknowledgment of te ao Māori and tikanga Māori (Māori world view and customs). There was little mention of the ethnicity of the different presenters (the majority of which are Māori) or the use of Māori language in the context of their favourite programmes (What Now? and Sticky TV. This indicates that the Pākehā-centricity comes from an expectation that Pākehā values will be included in their programming and it will be delivered to them in their preferred language, and that there is little value in the programming for them if this is not the case. The community must be created within these boundaries, echoing Bell's argument that "the loudest voice proclaiming identity is the one that persuades the nation". 84

${ }^{84}$ Bell, 1996 p.13 


\section{Conclusion}

These children illustrate clear expectations for local programming in their discussions of their likes and dislikes. There is a strong sense of creating a community for New Zealand children to feel a part of; however this community is also steeped in exclusions and limitations. The community that is being created is essentially for children who fit into a particular set of ideas about what a New Zealand child is. They are attracted to traditional tropes of New Zealand identity and a Pākehā frame when dealing with Māori language where, for the majority of participants, there is little desire to integrate this content into "our" programming, especially considering "they" (Māori) have their own channel. The need to feel included in the community of the programme is of utmost importance and Māori content has the potential to exclude a significant number of the participants. The ability to access the programme is decreased, making it less desirable for these some children. Their cultural identity is seemingly tied to being able to participate in an accessible community that provides them with the kind of representations that make them feel comfortable and included.

The idea of an exclusive community will be examined in more detail in the following chapter where it will be contrasted with the results found in the previous chapter. This will open out the complexities and conflicts that have emerged in the different discourses of cultural identity between creators and producers and begin to deconstruct the potentially conflicting discourses of a concept that is central to the existence of locally produced children's programming. 


\section{Chapter Five - Reflection versus Community Creation}

The aim of this research has been to examine the discourses surrounding cultural identity used by creators and audiences to give meaning to the genre of locally produced children's television in New Zealand. The previous two chapters have outlined the results from interviews with both groups. This chapter will compare the two studies and discuss in more detail the way that cultural identity has been conceptualised and understood. Cultural identity was framed in this research as being a socially constructed sense of belonging to a particular group that acquires meaning through discourse. The discussions with programme makers and children have illustrated that this sense of belonging is understood in different ways. The key difference is for the children interviewed, cultural identity was foremost about feeling connected to other children through a community that the programmes created. For programme makers, the focus was on reflecting children's worlds. These two conceptualisations will provide the frame for a discussion of the major connections and disconnections in the way that creators and audiences interact with cultural identity.

\section{Children and Cultural Identity}

The results from the focus group research demonstrate that the children interviewed have a particular set of expectations for their local programming. Cultural identity for these children is about the feeling of connection to a 'kids' only' community and being able to see and interact with other children through the programmes. This community, however, also has a series of exclusions. As well as a feeling that adults did not always understand what they wanted to see, participants exhibited what is arguably a learned discourse regarding issues of Pākehā identity and an interaction with some traditional associations and concepts regarding being a 'New Zealander'. The discussion of the likes and dislikes of the programming revealed a different way of interacting with cultural identity and a strong expectation that programming made in New Zealand would be accessible by offering them opportunities to participate and enter competitions. 


\section{Creators and Cultural Identity}

The funders and producers had a considerably broader frame of reference for the notion of cultural identity, not only through their life experience as adults, but also their active interaction with the concept in funding documents and programme proposals. There was a strong sense of reluctance and discomfort, however, with the idea of explaining or defining explicitly what cultural identity meant, and how it impacts on the way that they construct content. While definitions were considered not particularly "useful", there is an acknowledgement from creators of children's programming that there is value in reflecting a sense of cultural identity and that New Zealand has a distinct cultural identity that can and should be reflected. This issue of 'reflection', however, proved complicated with an attachment to traditional notions of 'New Zealandness' and the assumption that interactivity will 'naturally' produce an accurate depiction of their audience.

\section{Community Creation}

The bond that these children expect from their programming can best be described by Anderson's "imagined community", outlined in the first chapter as the way that a sense of national identity is fostered between members of a nation state that are unlikely to ever meet. The children ultimately want to feel part of a 'kids' only' community that is larger than their own social experience, and connect with children that are represented in a familiar social environment. It is important to recognise that rather than feeling connected to the narrative of the programmes themselves, the participants largely understood the programmes as their 'window' to other children. Programmes act as a facilitator of this connection between children rather than texts that are watched only for entertainment or distraction. As the discussions of Studio 2 illustrated, the connection is not with the presenters or celebrity guests and without the interaction with children the programme is viewed as "boring". 
The 'kids' only' community is related to knowing that they are potentially able to be a part of the programme. The discussions of What Now?s 'Spyrider' demonstrated that these children were not interested in the adult perspective of their town, they wanted to be able to see themselves and their friends taking part in different activities, and see similar groups of friends taking part in other towns. The preference for seeing larger groups of children over one or two children reinforces this notion of a community, where many children can take part in and feel connected to the programme.

\section{Accessibility and Connection}

A distinguishing factor of this connection is that it the community is accessible. They need to feel as though they could possibly appear on the show, and that the children they see on the programmes are similar to them.

The New Zealand broadcasting environment has largely created this need to foster a connection between New Zealand children as they can feel disconnected from programming that is created for a different market. New Zealand children are unable to participate in imported shows, they can not enter competitions, communicate with the programme makers or have the opportunity to be on a show and watch it being filmed. The broadcasting environment has also stifled the creation a diverse local children's schedule in New Zealand. It is not viable to produce shows similar in style to the popular Disney series such as Hannah Montana and The Suite Life of Zack and Cody that are considered favourites among the audience. This has created different expectations for local programming from the audience. Local programming provides an opportunity for interaction and participation, while imported material is viewed as being purely for entertainment.

The children interviewed demonstrated a desire for a tangible and accessible connection. This connection goes further than being able to enter competitions, it illustrates a desire to create a relationship that is special and different from the other forms of programming available to them. Here their 'kids only' community exhibits its first key exclusion; it is for 'New Zealand kids' only'. 
Positioning the Community

The community is also positioned within larger social discourses that impact on New Zealand identity. There is a strong relationship to New Zealand needing to feel connected to the rest of the world and that identity creation can be a Pākehā focussed process. The influence of these discourses creates a more complicated understanding of how children interact with cultural identity in this context. The children's connection to larger arguments regarding New Zealand identity illustrates the conflicting relationships that can exist within cultural identity.

A reproduction of these larger discussions regarding New Zealand identity is evident in the way that the children viewed their position as New Zealanders in relation to the rest of the world, as well as the way that they discussed an exclusive and Pākehā-centric connection to New Zealand programming. Claudia Bell has argued that discourses used by adults and wider society impact on the way that children understand their own cultural identity. She explains that "children recite received ideas, telling adults what is expected, what children think they want to hear... What children inevitably suggest is a recapitulation of the media's self-generating version of New Zealand". ${ }^{85}$ This "recapitulation" of ideas illustrates the impact that dominant representations of New Zealand identity can have on how the audience define cultural identity and suggests that programming created specifically for children is a potential site for perpetuating these discourses.

As well as providing children with a sense of connection within the New Zealand audience there is also a focus on being able to position New Zealand in a global context. There was a strong concern that only having access to New Zealand programming would cut them off from the rest of the world and make them less responsible global citizens. Cultural identity is conceptualised here as not only about how New Zealand children life their lives, but to also contextualise the importance of these experiences with the rest of the world. This places definitions of cultural identity within the global as well as the local, which is difficult given how the concept acts as the overarching condition for funding New Zealand content.

85 Bell, 1996, p.88. 
The most prevalent discourse that children connect with is a Pākehā-centric sense of belonging. This Pākehā-centric frame was expressed through a feeling of threat or disconnection during the use of Māori language and culture. Placing children's television in wider social discourses and power relationships between Pākehā and Māori is, as Turner describes it, an "inclusive exclusion" when constructing a New Zealand identity. ${ }^{86}$ The audience reaction to Pukana illustrates the community children connect to is ultimately a Pākehā community. While other cultures are acknowledged, it must be framed in a way that is understandable and relevant for Pākehā. Language was the ultimate barrier between the participants and Pukana and some exhibited a very defensive reaction to the suggestion that the programme was still a 'kids' programme'. While this can be expected from groups of children that are predominantly Pākehā, it was also an issue with Māori children and the groups from the bilingual programme who are in a stronger position to connect to the language and values being discussed. While the bilingual children liked Pukana they felt a stronger connection to programmes such as What Now? as the community that they are given access to is considerably larger. The need to feel connected to a larger community of New Zealand children appears to override other cultural connections.

While the Pākehā-focussed terms "kiwi" and "kiwiana" were more popular among the producers than the audience, the underlying ideas of these terms were present in the children's discussions. This illustrated a relationship between the discourses used by programme makers and their impact on the audience. Turner uses the positivity associated with "kiwi" in his larger argument regarding "inclusive exclusion"87, where privileged forms of identity (such as the "kiwi") exclude other members (such as Māori, migrants) from within the nation-state. This is arguably a way for Pākehā New Zealanders to assert a connection to the land and history of New Zealand, as Turner articulates, "for New Zealanders the importance of commitment to place may be so strong that this, in itself, makes them indigenous."88 These children were comfortable with Māori being used as signifier of a programme being from New Zealand, but were uncomfortable if Māori content, particularly

86 Turner p.87

$87 \mathrm{lbid}$

88 lbid 94 
language, made them feel disconnected from a programme and their opportunity for community.

The privileging of a connection between children over other forms of belonging raises questions about whether the Pākehā-centric aspect of the community is based in a wider opinions held by the audience, or if it is because this is the discourse used when programmes are created. The preference of a Pākehā view from children, and not only Pākehā children, is potentially based in the repetition and history of this style of identity formation within their programming. There appears to be an expectation that a Pākehā conceptualisation will give them access to a wider range of children in a familiar and comfortable format than programming that is designed for a more specific cultural audience.

\section{Reflection}

The producers, however, were reluctant to consider themselves in the role of constructers of a sense of cultural identity or as mediators of local orientation. Due to their engagement with the audience, programme makers' definitions of cultural identity were not considered to impact on content creation. This perceived engagement with programmes would ultimately "reflect" children's social realities back to them.

This term "reflection" was well utilised by producers and largely served as a shield from the notion of construction. 'Reflection' in itself indicates a connection and understanding of the audience, in order to know what it is that needs to be reflected there must be some kind of relationship with the audience. Phrases such as "reflecting kids' worlds" enabled producers to disassociate themselves from being in a position to set the agenda and tone for their programmes. While intended to distance themselves from being in a power position and 'creating' content for their audience it also acts to demonstrate the potential distance between programme makers and their child audience.

The emphasis on reflection further complicates a concept that is already discussed in very broad terms by funders and producers. The claims to 'reflect' their audience illustrates an 
avoidance of 'reflecting' on the creators own role. This evasion of self-reflection on their role in the construction of cultural identity for children can arguably result in a difficult and undefined middle ground for conceptualising cultural identity, where 'reflection' can not conceivably be achieved and 'construction' is an avoided and uncomfortable notion.

There is a conflict between being able to directly connect with a child audience while in the position of an adult programme maker, as programming has a number of external (and adult) requirements. Claims of reflection are easily muddied by issues of appropriate content and the need to provide children with educational material. While it can be expected that there is a filtering of content for a younger audience, it raises questions about why 'reflection' is such a central focus for the programme makers when their ability to 'reflect' children's experiences is ultimately affected by certain standards and expectations on children's content.

The discourse of reflection is arguably about the need to create a connection with the audience that goes against the inherent division between adult and child. While it is inevitable that programming for children is going to be created by adults, programme makers combat this inherent disconnection by aligning themselves as closely to their audience as they can. For example when What Now? create a mantra such as "we're not worthy" there is an attempt to invert the natural power relationship by placing the audience in the more dominant position and indicating that the programme makers are 'lucky' to be able to inhabit a children's space. This, however, arguably has the effect of reinforcing the distance between the producer and the audience by emphasising the different roles that the children and the adult programme makers traditionally occupy. This is not to suggest that adults are not capable of creating children's programmes or that children should somehow be solely responsible for creating their programming. The issue here is that there are inherent difficulties in the producers' claims to 'reflect' children's worlds and their discomfort in suggestions to the contrary.

This distance is seen in the conceptualising of their audience's interaction with cultural identity as a community of "kiwi kids", where programme makers were trapped in nostalgic discourses of 'New Zealandness'. The notion of a "kiwi kid" comes largely from a discourse 
of a nostalgic New Zealand childhood that a modern child audience does not necessarily experience. As illustrated in the earlier discussion of Turner's work, "kiwi" is arguably a term used as cultural capital, as well as one that is the result of a further power relationship designed to further define (and therefore exclude) the notion of a New Zealander. 89 There was a strong emphasis from the producers and funders to be 'representative' of different aspects of life for New Zealand children. These representations, however, were generally etched in a fascination with small town New Zealand where a particular set of quirks could be entertained and explored. The simplicity of this small town frame is seemingly related to this potential back projection of a 'simpler time' into children's programming. It suggests that children exist is a more simple and 'pure' space in the minds of the adult programme makers. This view of children would further inhibit the ability of programme makers to accurately "reflect kids' worlds".

This association between a 'New Zealand identity' and the traditional imagery and ideals is discussed by Bell. 'New Zealandness', according to Bell, is portrayed as a homogenous, egalitarian "simplified identity"90, within which all groups are subsumed under one ideology and dominant set of national symbols. Iconography and notion of "kiwiana" held particular importance for producers, through the ability to act as cultural shorthand and are therefore easily integrated into games and competition. This exposes children to a particular way of signifying New Zealand identity that is not just about providing a "reflection". Bell rationalises a relationship to nostalgia as these icons connect to an elided and "charming"91 sense of social history and context, reinforcing the positive Pākehā identity creation discussed earlier. She argues that the 'us' reflects a Pākehā focus that maintains the cultural dominance of "middle class Pākehā values".92 The connection felt with Pākehā values was exhibited by children in the earlier discussions, demonstrating a connection to this idea for the way that they define their cultural identity. This raises questions regarding the ability of creators to "reflect" a way of life for New Zealand children without overcomplicating it with a historic sense of being a "kiwi".

\footnotetext{
${ }^{89}$ Bell, 1996, p.132.

$90 \mathrm{lbid}$.

91 lbid p.180.

$92 \mathrm{lbid}$.
} 
This dominance of Pākehā values was articulated in more indirect ways by the majority of creators. They continued the idea that other cultures should be assimilated into a Pākehā frame through their discussions of what they consider to be a reflection of 'New Zealandness'. The inclusion of Māori content and presenters was discussed in a way that involved Māori needing to explain themselves to a Pākehā audience and become a part of "their world". This was seen through some creators' discussions of Māori ("brown") presenters and through the need to frame Māori content in a way that is appealing to a mainstream audience.

Most programme makers also inevitably discussed ethnicity, an issue not discussed by the children. Ethnicity is a central marker of how creators understand representations of cultural identity. It was given a particular focus as a way to represent a sense of 'culture' and a diverse range of ethnic backgrounds of participants was used as a form of cultural representation. However this was something that was considered to occur "naturally" except in the case of What Now? where they were open with their struggle to find "an Asian kid, a Māori kid..." for their promos. The presenters of the programme were also mentioned as a way of representing different ethnicities, however it was quickly pointed out that this also occurred naturally and was not an active consideration when finding new presenters.

The ability of this to be a 'natural' process has similar difficulties to the term 'reflection'. The defence of ethnic diversity as a 'natural' occurrence is weakened by the prime place that it occupies in creators understanding of cultural identity. By naming ethnicity, it illustrates a more conscious relationship between ethnicity and cultural identity. Having Māori presenters was mentioned by the children interviewed as being a way of signifying a programme is made in New Zealand, but there were stronger associations with language and culture rather than visual differences between presenters and children featured in the programmes. This illustrates a larger difference between creators and the audience, where the children were more interested in programme content and did not discuss the aesthetics of the programme in great detail. They were more interested in what the other children were doing rather than where it was taking place, further reinforcing that cultural identity for them is through connection, rather than a visual representation or "reflection". 


\section{Product of the Environment}

Producers are required to actively negotiate between the two different sets of expectations between NZOA and the broadcasters. It is this "middle ground" where producers interact with and ultimately create their understanding of cultural identity. This negotiation also clearly positions programme makers as creators of content rather than a vehicle for 'reflecting' a sense of identity or community for their audience. The admission that producers are known to produce two separate proposal documents for broadcasters and NZOA demonstrates an 'in-between' space that cultural identity is forced to occupy. This indicates that there are markedly different expectations from programming, and that the programme itself is likely to end up somewhere between these two different ideas. A tension between providing culturally relevant programming and still being engaging and entertaining places further demands on creators' ability to 'reflect' children's worlds.

This tension between 'entertainment' and 'culture' also requires locally produced children's television to position itself with a 'global' outlook. It was important that being a New Zealander is not seen as being any 'better' than other countries and that New Zealand content and issues were not solely focussed on, a discourse that children had adopted earlier in this chapter. This impacts on cultural identity and local content through its need to be actively defined by the other content and identities available.

A positioning such as this also provides insight into the connection to a nostalgic sense of cultural identity. The use of a somewhat underdeveloped and traditional frame for cultural identity may be due to the recognition that there is actually limited space for expressing New Zealandness within the programming, even though this is a funding requirement. These traditional representations are able to provide a cultural shorthand of 'New Zealandness'.

It was suggested earlier that the children's sense of community is affected by the repetitive and expected format of the New Zealand produced programming available to them. Limited funds have kept the style and format of programming stagnant. The variety style of programming is cheaper to produce and a longer, daily programme can be produced rather 
than a shorter drama series or game show. While this does create a sense of connection and community, it also starts to create a local/imported content divide, reinforcing that locally produced programmes look different and occupy a different place in their television habits, and potentially shaping how they will continue to differentiate local programming as adults. These creators illustrate that children are not given access to a diverse range of expressions of cultural identity and as a result the children want to foster their own sense of belonging by being exposed to a wide community of other children.

\section{Creating Connections}

The differences between creators and audiences exhibited in the previous sections raise questions about how audiences' need for connection can be fostered by creators. A way of working through this issue is examining in more detail what the children interviewed currently like and dislike in the programming available. This section will evaluate the participants' reactions to Studio 2 and What Now?s 'Spyrider' as examples of how this desired connection can be encouraged, as well as considering a potential area of disconnection in the future.

\section{Studio 2}

Studio 2s producers discussed a philosophy of interaction that appeared to match with the audience expectations of connection, however, paradoxically the programme was the most disliked by the children interviewed. Studio 2 is focussed on utilising technology in order to allow their audience to connect to the programme. The ideal of connection here is viewed differently by the audience. They expect a connection to be fostered between other children rather than with the programme. The programmes are framed in the role of mediator, they provide a medium for children to see other children as well as new experiences and ideas that they may find interesting. The children interviewed considered the ability to see other children, particularly seeing other children participate in an activity or go through a new experience as making a programme more enjoyable to watch. 
As the show that prides itself on being the most interactive and highly involved with communication technologies there is a focus on fostering an online community through TheHub. When this online community was interacted with during the programme through presenters logging onto The-Hub and bringing up forums and photos for viewers to see, there was a sense of disengagement from the children interviewed. There is a connection created through seeing another child on screen and that this experience is diminished through the introduction of another communication medium. It is more difficult to establish a relationship with other members of the audience through two methods of mediation, television and computer.

A sense of community was also lost for Studio 2 through a lack of children within the programme that the audience could a form connection with. There is no studio audience and a significant amount of the interaction with children takes place through email and text rather than the face to face interaction seen in the other programmes. This resulted in the interaction between the presenters and guests without the presence of children being seen as "boring".

\section{'Spyrider'}

What Now?'s 'Spyrider' was the favourite part of all the programmes for the children interviewed. The travelling satellite allowed a significant portion of the programme to take place in a different town each week. The participants felt a strong sense of attachment and connection to the presenter, Tamati and were excited to see a large number of different children in different towns participating in games and competitions. The tangible connection that Tamati provided to the programme and other children is different to the mediated experience in Studio 2. 'Spyrider' provided an interactive experience that the children knew they could potentially be a part of, and when Tamati visited Linton they were able to have a particular interaction with the programme that they felt was significant and memorable. They were able to participate in an experience that they felt united them as a community. 
The central difference between Studio 2 and 'Spyrider' is the ability to actually see interaction with other children. The use of a studio audience and having regular guests that were children would also increase the connection that was felt to the programming. The community that children desire is a visual community, in order to create a sense of belonging they need to be able to see the wider community that they wish to belong to.

While What Now? is able to have a segment such as 'Spyrider' partly because they are a weekly show and Studio 2 produces 5 shows a week, the significant element here is the need to create a human connection for children despite an expectation of a high interest and usage of communication technologies.

\section{A Future Disconnection}

A future concern for the creators of programming was the issue of new technologies and the impact that this may have on the size and accessibility of the audience. The rapid progression of new technologies and the possibility of children choosing these other forms of technology over watching and participating in a programme is a central concern for children's television globally, and consequently is also a concern to local producers and funders. All the shows under discussion have started to utilise communication technologies to improve participation and interaction with the programming, mostly through websites. Studio 2 have gone further with The-Hub and created special content and outtakes that can only be viewed online.

While the children interviewed for this project were experienced with different kinds of communication technologies they were not interested in seeing and using this type of technology in their programming. As seen in the earlier discussion regarding Studio 2 attempting a process of double mediation, there is a far greater focus for these children to be able to interact with a human connection. They enjoyed the possibility of being able to see the presenters and participants in real life as well as potentially be a part of any of the shows. 
To illustrate the significance of this desire for human connection a comparison can be made between the current concerns in the public service environment in the UK. In order to compensate for the decreasing ratings for children's programming due to technology such as gaming consoles and the internet, commissioners are now focussing on short animated content that can be delivered on a variety of media platforms (Internet, cell phones etc) on demand. 93

This is where a future disconnection between the creators and their specific audience may occur. Cultural identity, for the children in this project, is the creation of an accessible community that allows for interaction and connection between members of the audience. Creating content that is essentially more individually based and 'on-demand' will potentially cause the programming to be less engaging for the audience. As the internet is essentially a global broadcaster, programme makers can open out the community and opportunity for participation to a wider global audience. However, this is not necessarily an attractive quality for their New Zealand audience. Potentially taking away, or at least diminishing the unique appeal and connection to the programme and its participants illustrates a miscalculation of how the audience understands cultural identity and the role of local programming in facilitating a connection to it.

\section{Conclusion}

This thesis has examined the role that cultural identity plays in locally produced children's programmes in New Zealand. There is a number of complexities involved in using such a fluid concept as a requirement when creating children's programming, as there is a range of definitions and interpretations available. The children involved in this research exhibited a desire to connect to a larger community of children, while programme makers were largely distracted by the claim to 'reflect' an interpretation of a community that was sometimes tied to a nostalgic sense of 'New Zealandness'. This differentiation between creating a community and 'reflecting' a pre-existing community demonstrates a disconnection in the way that creators and audiences interact with cultural identity.

${ }_{93}$ Chalmers, Anna (2007). "Shorter is Sweeter for kids' shows" in The Dominion Post, November 7, 2007, p. A13 
This disconnection potentially impacts on the relationship children have with television more generally, as well as the larger area of New Zealand television. For children there is still a significant space for consideration of how they interact with and create a connection to other kinds of television (such as imported animation, locally produced prime time television, imported prime time television) as well as how this connection is utilised in their relationship with new media. For New Zealand television more generally, this research opens up the potential for a deeper understanding of differences in how cultural identity is understood by programme makers and audiences and the impact this may have on audiences' engagement with particular programmes.

Cultural identity is a changeable concept. While this means it is adaptable and therefore useful for creating television that has to appeal to a wide audience, it is also somewhat unpredictable. It is this unpredictability that requires it to be constantly evaluated for both creators and audiences of New Zealand television. 


\section{Bibliography}

Anderson, Benedict (1991). Imagined Communities, London: Verso.

Barbour, Rosaline S \& Kitzinger, Jenny (1999). Developing Focus Group Research: Politics, Theory and Practice, London: Sage.

Barker, Chris (1999). Television, Globalization and Cultural Identities, Buckingham: Open University Press.

Bell, Claudia (2004). "Kiwiana Revisited" in Claudia Bell and Steve Mathewman (eds) Cultural Studies in Aotearoa New Zealand: Identity, Space and Place, Oxford: Oxford University Press: 175-87.

Bell, Claudia (1996). Inventing New Zealand: Everyday myths of Pākehā Identity, Auckland: Penguin.

Belton, Teresa (2001). "Television and Imagination: and investigation of the medium's influence", Media, Culture and Society, 23(6): 799-820.

Billig, Michael (2004). Banal Nationalism, London: Sage.

Boden, Sharon (2006). "Dedicated followers of fashion? The influence of popular culture on children's social identities", Media, Culture and Society, 28(2): 289-298.

Buckingham, David (1993). Children Talking Television: The Making of Television Literacy, London: The Falmer Press.

Buckingham, David, Davies, Hannah, Jones, Ken \& Kelley, Peter (1999). Children's Television in Britain, London: British Film Institute.

Buckingham, David \& Bragg, Sara (2004). Young People, Sex and the Media: the facts of life?, New York: Palgrave MacMillan. 
Chalmers, Anna (2007). "Shorter is Sweeter for kids' shows" in The Dominion Post, November 7, 2007, A13.

Colmar Brunton (2000). Children and Young People's Attitudes to TV Programming and Local Content, Qualitative Research prepared for New Zealand On Air, available at <http://www.nzonair.govt.nz/files/about/C_YP_Attit.pdf> version current at 23/3/08.

Davies, Hannah, Buckingham, David \& Kelly, Peter (2000). "In the Worst Possible Taste: Children, Television and Cultural Value", European Journal of Cultural Studies, 3(1): 5-25.

Dockett, Sue \& Cusack, Mella (2003). "Young children's views of Australia and Australians", Childhood Education, 79(6): 364-68.

Dunleavy, Trisha (2005). Ourselves in Primetime: A History of New Zealand Television Drama, Auckland: Auckland University Press.

Federal Communications Commission (2007). FCC Fact Sheet: Children's Television Programming, available online at http://www.fcc.gov/Bureaus/Mass_Media/Factsheets/kidstv.txt, version current at 6/3/07.

Fleras, Augie (1998). “Working through Differences”, New Zealand Sociology, 13(1): 62-96.

Friedman, Jonathan (1994). Cultural Identity and Global Process, London: Sage.

Gray, Ann (2003). Research Practice for Cultural Studies, London: Sage.

Hall, Stuart (1997). "The Work of Representation", in Stuart Hall (ed) (1997). Representation: Cultural Representations and Signifying Practices, London: Sage: 15-64.

Horrocks, Roger (2004). "Construction Site: Local Content on Television”, Chapter 16 in Roger Horrocks and Nick Perry (eds.) Television in New Zealand: Programming the Nation, Melbourne: Oxford University Press: 272-285. 
Howard, Sue and Gill, Judith (2001) "It's Like We're a Normal Way and Everyone Else is Different: Australian children's constructions of citizenship and national identity", Educational Studies, 27(1): 87-103.

Jackson, Sue, Low, Jason, Gee, Susan, Butler, Carly \& Hollings, James (2007). Children's Media Use and Responses: a review of the literature, Wellington: Broadcasting Standards Authority.

Kline, Stephen (1996). Out of the Garden: toys, TV, and children's culture in the age of marketing, London and New York: Verso.

Krueger, Richard A. \& Casey, Mary Anne (2000). Focus Groups: A practical guide for applied research, Third Edition, London: Sage.

Lavranos, Eileen (2003). “Children's Television Programming in New Zealand: Like the Kiwi an endangered species?", paper presented at ANZCA03 conference, Brisbane, July 2003.

Lealand, Geoff (2004), "Children's and Youth Television: The Most Important Genre?" in Roger Horrocks and Nick Perry (eds) Television in New Zealand: Programming the Nation, Melbourne: Oxford University Press: 152-66.

Lealand, Geoff (2001). "Some things change, some things remain the same: New Zealand Children and Media Use" Studies in Media and Information Literacy Education, 1(1): 1-9.

Lealand, Geoff \& Zanker, Ruth (2002). "'You'd have to change the world': Children and Media in New Zealand in the New Millennium", available online at <http://www.netsafe.org.nz/Doc_Library/netsafepapers_lealandzanker_millennium.pdf> version current at 31/10/06.

Liu, James H, McCreanor, Tim, McIntosh, Tracey and Teaiwa, Teresa (2005). "Introduction: Constructing New Zealand Identities" in Liu, McCreanor, Mclntosh and Teaiwa (eds) New Zealand Identities: Departures and Destinations, Wellington: Victoria University Press: 11-20. 
Lustyik, Katalin (2005). "Localising the Global in New Zealand? Nickelodeon and the institutional logics of media conglomeration", paper presented at the ANZCA annual meeting, Christchurch, 4-7 July 2005.

Meijer, Irene Costera (2001). "The colour of soap opera: An analysis of professional speech on the representation of ethnicity", European Journal of Cultural Studies, 4(2): 207-230.

Messenger Davies, Máire \& Mosdell, Nick (2006). Practical Methods for Media and Cultural Studies, Edinburgh: Edinburgh University Press.

Messenger-Davies, Marie (2001). "Children's Television” in Glen Creeber (ed) The Television Genre Book, London: BFI Publishing: 96-9.

Murdock, Graham (1997). "Public Broadcasting in Privatised Times: Rethinking the New Zealand Experiment" in Paul Norris and John Farnsworth (eds) Keeping It Ours: Issues of Television broadcasting in New Zealand, Christchurch: New Zealand Broadcasting School, Christchurch Polytechnic, 9-33.

New Zealand On Air, (2003). The Furture of Public Broadcasting: The Experience in 6 Countries, Wellington: New Zealand On Air.

NZ On Air, (2000). NZ On Air Children's Programming Strategy, available at $<$ www.nzonair.govt.nz> version current at 26/2/08.

Norris, Paul (2004). "Reshaping Public Broadcasting: the New Zealand Experience 1988-2003" available at Institute of Public Policy Research, <http://www.ippr.org.uk/uploadedFiles/projects/NorrisNZ2.PDF> version current at 28/3/08

Norris, Paul; Pauling, Brian; Lealand, Geoff; Huijser, Henk; \& Hight, Craig (1999). Local Content and Diversity: Television in Ten Countries: A Report for NZOA, Wellington: New Zealand On Air.

Parlane, Josephine (2003). "Street Legal: National Identity in a New Zealand Drama Series", MA Thesis, University of Auckland. 
Pecora, Norma, Murray, John, Wartella, Ellen (2006). Children and Television: 50 years of research, New Jersey: Lawrence Erlbaum.

Rubin, Herbert J. \& Irene S. (1995). Qualitative Interviewing: The Art of Hearing Data, London: Sage.

Seale, Clive (2001). Researching Society and Culture, London: Sage.

Shepherd, Ngaire (2007). Seen and Not Heard? Cultural Identity in New Zealand produced children's programming, paper presented at MEDIANZ conference, Wellington, February 2007.

Smith, Anthony (1991). National Identity London: Penguin.

Strasburger, Victor C. \& Wilson, Barbara J. (2002). Children, Adolescents and the Media, Thousand Oaks: Sage Publications.

Strauss, Anselm \& Corbin, Juliet (1990). Basics of Qualitative Research: Grounded Theory Procedures and Techniques, London: Sage.

Tomlinson, John (1999). Globalization and Culture, Chicago: University of Chicago Press.

Tomlinson, John (1991). Cultural Imperialism, London: Pinter Publishers.

Turner, Stephen (2007). "Inclusive Exclusion: Managing Identity for the Nation's Sake in Aotearoa/New Zealand", Arena, 28: 87-106.

TVNZ (2007). A Successful Past, an Exciting Future, TVNZ Corporate Brochure, available at $<$ <ttp://tvnz.co.nz/view/about_tvnz_index_skin/816472> version current at 28/3/08.

Walters, Reece \& Zwaga, Wiebe (2001). The Younger Audience: Children and Broadcasting in New Zealand, Palmerston North: Dunmore Press. 
Wimmer, Roger D. \& Dominick, Joseph R. (eds) (2003). Mass Media Research: An Introduction, Belmont: Thomson Wadsworth.

Zanker, Ruth (2004). "Commercial Public Service Children's Television: Oxymoron or Media Commons for Savvy Kids?" European Journal of Communication, 19(4): 435-455.

Zanker, Ruth (2001). What now? : a New Zealand children's television production case study, PhD thesis, Waikato University.

Zanker, Ruth (1999). "Kumara Kai or Big Mac Pack?: Television for Six to 12-year-olds in New Zealand" in John Farnsworth and lan Hutchison (eds) (2001) New Zealand Television: A Reader, Palmerston North: Dunmore Press: 270-9. 


\section{Appendices}




\section{Appendix 1: Topic List for Interviews with Funders and Producers}

\section{$\underline{\text { Topic List }}$}

\section{Topic 1: Introduction}

- Explanation of the project

- Interviewee's professional background and experience

\section{Topic 2: The Child Audience}

- Key objectives of their programme / organization

- Children's role in these objectives

- Views on the child audience

\section{Topic 3: Children's Programming}

- Ideal themes/issues of a children's programme

- Key desirable characteristics of a locally produced programme

- Challenges/triumphs in dealing with these themes

\section{Topic 4: Cultural Identity}

- Definitions of cultural identity and its role in children's television

- Reflections of a New Zealand way of life for children

- Appealing to/ creating a good citizen

- Popular culture and cultural identity

- The interest of the child audience in New Zealand themes

- Māori interests and programming

\section{Topic 5A: Scheduling (For Funders)}

- Key objectives of the after-school schedule

- Local programming fitting the objectives

- Ideal characteristics of a children's brand (local and international)

- Cultural identity as a part of the schedule

\section{Topic 5B: Programme Examples (For Producers)}

- Challenges/triumphs faced in creating and maintaining the programme

- Fostering cultural identity

- Demands of funding and maintaining an audience

- Expressing cultural identity

- Interaction with pop (US) culture 


\section{Topic 6: Future Developments}

- Ideal situation for children's programming

- Challenges in the current situation

- Future plans/ intentions for children's programming and the audience 


\section{Appendix 2: Topic List for Focus Group Research with Children}

\section{Topic List}

\section{Topic 1: Introduction}

- Explanation of what they will be looking at

- Opinions of TV, favourite programmes, how much they watch etc

\section{Topic 2: After-school programming}

- What they do after school

- What do they watch after school

- What do they like/dislike about TV after school

\section{Topic 3: Studio 2 (show short clip)}

- Reactions to programme - likes/dislikes

- Changes they would make to the programme

\section{Topic 4: Sticky TV (show short clip)}

- Reactions - likes/dislikes

- Changes that could be made

- $\quad$ Comparisons to Studio 2

\section{Topic 5: What Now? (show short clip)}

- Reactions - likes/dislikes

- Changes that could be made

- Comparison to Studio 2, Sticky TV

\section{Topic 6: Pukana (show short clip)}

- Reactions - likes/dislikes

- Changes that could be made

- Comparison to Studio 2, Sticky TV, What Now?

\section{Topic 7: Programme Experience}

- Favourite/Least Favourite of four examples - Why?

- Where are the programmes made? How can you tell?

- Experience in participating in programmes (been on the shows, entered competitions etc)

- Used websites of programmes? Like/Dislike?

- General discussion of New Zealand programmes - like/dislike? Able to name others? 